\title{
Roughness Evaluation for Distinguishing Fresh and Sheared Rock Joint Surfaces with Different Sampling Intervals
}

\section{$\operatorname{AUTHOR}(\mathrm{S}):$}

Zhang, Jintong; Ogata, Sho; Kishida, Kiyoshi

\section{CITATION:}

Zhang, Jintong ... [et al]. Roughness Evaluation for Distinguishing Fresh and Sheared Rock Joint Surfaces with Different Sampling Intervals. International Journal of Geomechanics 2021, 21(12): 04021231.

ISSUE DATE:

2021-12

URL:

http://hdl.handle.net/2433/265479

\section{RIGHT:}

This material may be downloaded for personal use only. Any other use requires prior permission of the American Society of Civil Engineers. This material may be found at https://doi.org/10.1061/(asce)gm.1943-5622.0002220.; This is not the published version. Please cite only the published version. この論文は出版社版でありません。引用の際には出 版社版をご確認ご利用ください。 


\title{
Roughness evaluation for distinguishing fresh and sheared
}

\section{rock joint surfaces with different sampling intervals}

\author{
Jintong Zhang ${ }^{*}$, Sho Ogata², Kiyoshi Kishida ${ }^{3}$ \\ ${ }^{1} \mathrm{Ph} . \mathrm{D}$. Candidate, Department of Urban Management, Kyoto University, Kyoto 615-8540, Japan. \\ *Corresponding author: zhang.jintong.38w@st.kyoto-u.ac.jp \\ ${ }^{2}$ Assistant Professor, Department of Civil Engineering, Osaka University, Suita 565-0871, Japan \\ ${ }^{3}$ Professor, Department of Urban Management, Kyoto University, Kyoto 615-8540, Japan
}

\section{Abstract}

The subtle alteration of surface geometry from a fresh surface to a sheared surface usually results in a considerable variation in the shear strength of jointed rock mass. Through profiling surfaces of the granite joints before and after the shear tests, an evaluation scheme was newly proposed by determining a desirable characteristic index and sampling interval of surface measurement in order to distinguish fresh and sheared joint surfaces quantitatively. The measured data demonstrated that although the mean $Z_{2}$ (root mean square first derivation) values of all the profile lines were confirmed reasonable for estimating the $J R C$ (joint roughness coefficient) value of the fresh joint surface, it could not completely evaluate the roughness of the sheared joint surfaces. Meanwhile, the distribution of slope angles, as the characteristic parameter, was proved enable to clearly distinguish the fresh and sheared rock joint surfaces incorporating the small sampling scales $(<=0.1 \mathrm{~mm})$. The numerical simulations implemented in a mechanical shear model could confirm the critical effect of a slight change in surface geometry, and further prove that the sampling interval of $0.1 \mathrm{~mm}$ could sufficiently capture the evolved "waviness" and "unevenness" of rock joint surfaces. Overall, it was 
confirmed that the results of our study provide new clues for evaluating the surface roughness of fresh and sheared rock joints and can be beneficial for understanding the variation of surface geometry during the shear process.

Key words: Roughness, root mean square, surface alteration, sampling scale, slope angle

\section{Introduction}

The mechanical behaviour of a discontinuous rock mass is often governed by the thoroughgoing joints rather than the intact rock (Asadollahi and Tonon 2010). Notably, the geometrical characteristics of the joint surfaces (i.e., roughness) directly affect the strength and the friction behavior of the jointed rock (Barton 1973; Barton 1976; Byerlee 1978). An even slight change in the surface geometry, from a fresh surface to a sheared surface, usually results in a considerable variation in the shear behaviour of the discontinuous rock mass. Nevertheless, research to quantitatively clarify the difference between fresh and sheared joint surfaces has rarely been conducted.

In the cycles of shear experiments, it has been observed that a change in asperity has a critical influence on the mechanical behaviour of a discontinuous rock mass (Lee et al. 2001). Grasselli (2006) pointed out that the difference in peak resistance between the first shear test and the subsequent shear test is attributed to the change in micro-roughness. Hong et al. (2016) and Jiang et al. (2020) also confirmed that the degradation of smallscale asperities plays a significant role in mobilizing the peak shear strength. Therefore, the alteration of the surface geometry resulting from the shearing, namely, the difference in roughness between the fresh and sheared surfaces, should be distinguished and recognized as an essential factor for various research issues related to jointed rock (e.g., the drop in peak shear strength of the rock joint during cyclic shear tests and the 
constitutive model for a sheared rock joint reflecting the surface roughness).

To date, although some parameters have been proposed to grasp the rock joint asperity in shear cycles, a specific parameter that enables to clearly detect the change of asperity between fresh and sheared joint surfaces has not been established well. For example, dilation angle was used to describe the degradation of asperity in the cyclic shear experiment (Plesha 1987; Lee et al. 2001). However, it must be obtained only after the shear experiment instead of roughness evaluation before the experiment. In addition, despite the widely used statistical parameter, the root mean square first derivation $\left(Z_{2}\right)$, that have previously been presented to evaluate the roughness of the fresh surface of natural rock joint (Myers 1962; Yu and Vayssade 1991; Zou et al. 2019), the applicability of the parameter for the sheared surface has not been clarified and requires corroboration. Hence, it is necessary to map the features of surface morphology ahead of the shear test and to determine a parameter that can clearly distinguish the fresh and sheared joint surfaces.

In the last few decades, considerable efforts have been made to quantify the roughness of fresh surfaces according to the geometric characteristic (Tse and Cruden 1979; Yu and Vayssade 1991; Tatone and Grasselli 2010). Although various sampling approaches have been utilized to measure the surface geometry, there are many uncertain issues involved in determining the appropriate profiling procedure, such as the number of contour lines on the joint surface, the sampling interval on the profiling line, and the profiling accuracy and precision of the measuring instrument. Moreover, these techniques need further validation for clarifying the fresh and the sheared rock joint surfaces.

The method of typical profiling lines is recommended by ISRM (1985) to estimate the roughness of the joint surface. However, Barton and Choubey (1977) did not explain 
how to select the typical profiles or how many profiles should be chosen to represent the joint roughness coefficient $(J R C)$ of an entire joint surface. Some studies presented simple methods for choosing typical profiles for determining JRC values. Tatone and Grasselli (2010) suggested a few center profiling lines on the joint surface that could be taken as the representative roughness profiles for the entire joint surface. Zhang et al. (2014) reported that the $J R C$ values could be evaluated by the root mean square first derivation $\left(Z_{2}\right)$ values of three profile lines (two edge lines and one center line) on the joint surface. Liu et al. (2017) confirmed that ten $Z_{2}$ values could be calculated by ten evenly distributed surface profiles and that the maximum $Z_{2}$ value of them is appropriate for predicting the $J R C$ values. However, there is a significant difference between roughness profiles, especially on the surface of a natural rock fracture (Kulatilake et al. 1995). The choice of a specific profile, used to estimate the surface roughness, may strongly affect the JRC values (Reeves 1985; Belem et al. 2000; Grasselli et al. 2002). Hence, the above methods are under examination for use in determining the number of profiling lines.

The sampling intervals have a significant influence on the measurements of the initial surface roughness (Tatone and Grasselli 2013). In the past, sampling intervals from $0.25 \mathrm{~mm}$ to $2.0 \mathrm{~mm}$ were mainly utilized to develop relationships between the statistical parameters and the JRC values (Yu and Vayssade 1991; Jang et al. 2014; Yong et al. 2018). Some researchers have stated that the determined interval should have the capacity to map the "waviness" and "unevenness" of a fracture surface relative to its mean plane (Yang et al. 2010; Hong et al. 2016). Myshkin et al. (1998) indicated the necessity to measure the joint surface at nanometer orders of magnitude resolution for investigating the changes in the morphology of a sheared surface. However, a claim was made in another research that it is unnecessary to decrease the sampling interval to less than $0.5 \mathrm{~mm}$ because intervals 
smaller than $0.5 \mathrm{~mm}$ cannot bring about any improved detection of the theoretical/empirical relationships for defining the $J R C$ values (Tatone and Grasselli 2010). Therefore, the sampling interval must be determined in order to characterize and distinguish the fresh and sheared joint rock surfaces.

In addition, diverse measurement instruments have been applied to capture the geometry of the joint surface, such as profile combs (Tatone and Grasselli, 2010), laser scanners (Sharifzadeh et al., 2008; Yong et al., 2018; Renaud et al., 2019), advanced topometric sensors and photogrammetry (Grasselli et al. 2002; Tatone and Grasselli 2013, Xia et al. 2014), and a 3D optical profilometer (Zou et al. 2019). Although various levels of accuracy and precision have been confirmed for mapping the surface characteristic with these devices, the influence of the measuring accuracy and precision on the calculation of the statistical parameter has rarely been considered in detail.

The main objective of the present study is to propose an evaluation method to quantitatively distinguish the pre- and post-sheared surfaces of rock joints by determining an appropriate characteristic index and sampling interval. In previous, a desirable and useful evaluation method that can perform the above distinction well has not been established. In this study, the repeated shear tests with jointed granite were conducted and the joint surfaces were profiled with different sampling intervals before and after the shear tests. In the profiling process, two devices were employed to confirm the influence of the measurement accuracy and precision. Then, the corresponding relationships between parameter $Z_{2}$ and the $J R C$ values were examined for the pre- and post-sheared joint surfaces, respectively. Subsequently, a characteristic parameter, able to capture the changes in the distribution of the apparent dip angles with the fresh and sheared joint surfaces, was adopted and validated. Finally, the effects of a slight change in surface 
geometry on the shear behavior of rock joints and the sensitivity of sampling intervals for

capturing the surface alteration were further examined by numerical simulations employing the mechanical shear model based on the detailed topography information.

\section{Description of Experiments}

Profiling experiments were performed on joint surfaces before and after the shear

process by two kinds of remote no-contact profiling techniques to obtain the digital geometric data. The repeated shear tests were conducted on the joint rock under constant normal stress to investigate the evolution of shear strength in fresh and sheared joint rock.

The characteristic indexes were calculated and analyzed with different sampling intervals according to the profiled digital data.

\section{Specimen Preparation}

Granite specimens were sampled from a quarry located at Inada district (specimen G1 and G2) and a tunnel located at Inagawa district (specimen G3 and G4), Japan. The mineral compositions of granite specimens were determined by the X-ray diffraction (XRD) method. The Inada samples (G1 and G2) consist of $56.75 \%$ quartz mineral and weathered specimen (G3 and G4). 
specimen was formed with a cross-section of $120 \mathrm{~mm} \times 80 \mathrm{~mm}$ and a height of $50 \mathrm{~mm}$. Finally, all the samples were cast with cement into steel sample boxes to bring them to the final size (a cross-section of $120 \mathrm{~mm} \times 80 \mathrm{~mm}$ and a height of $120 \mathrm{~mm}$ ). This ensured a snug fit in the shear box and provided a flat surface for seating and loading the samples. Contour maps of the joint surfaces of all the specimens are shown in Fig. 1. Partial profiles are exhibited in Figs. 1(a) and (b).

\section{Test Equipment}

In this study, two kinds of remote no-contact profiling techniques were employed to measure the roughness of the rock joints, as shown in Fig. 2. One of the widely used instruments is the laser scanner (Fig. 2(a)), which can calculate the travel distance of the pulsed beam to record the geometrical information of the target surface. Hereafter, it is called the laser scanner method. This roughness profiling system consists of a laser scanner with a resolution of $0.5 \mu \mathrm{m}$ and an $\mathrm{X}-\mathrm{Y}$ positioning table having an accuracy of $\pm 15 \mu \mathrm{m}$ and precision of $\pm 15 \mu \mathrm{m}$. This system can capture the detailed information of the surface, but is complicated and time-consuming to utilize at small sampling scales $(<250$ $\mu \mathrm{m})$. Thus, the rough joint surface is measured at intervals of $250 \mu \mathrm{m}$ during the roughness profiling work. The measured data are input into the computer in the digital cloud format. Data for joint surfaces with a total of $315 \times 475$ points and areas over $120 \times 80 \mathrm{~mm}^{2}$ are extracted. The measurement allowance spot dimensions are $45 \mu \mathrm{m}^{2} \times 20 \mu \mathrm{m}^{2}$. One shortcoming of the laser scanner is that some errors occur due to the existence of micropoints that are smaller than the allowance spot dimensions. Another shortcoming of the scanner is the diffuse reflection from dark and bright minerals on the surfaces. Error points can be counted by identifying the measurement noise. In the case of fresh specimen G1, there were 13270 error points in the lower surface and 9828 error points in the upper 
surface, and the ratios of errors in the lower and upper surfaces were $8.8 \%$ and $6.6 \%$, respectively. The digital data at the error points are correctly calibrated using the average height values of neighboring points.

Another technique for mapping the surfaces is an optical cutting method (or light section method) which has extremely high accuracy and excellent repeatability. As depicted in Fig. 2(b), this technique adopts projections of light to emit banded white light on the objective surface from two different angles. Hereafter, the term optical profiler is used to describe this approach. The reflected white light is received by a triple-telocentric lens and recorded by a complementary metal oxide semiconductor (CMOS) sensor. The principle of optical triangulation is applied during the computation process in order to generate point clouds. In this work, a device is employed for optical profiler (Keyence VR-3200) to map the surfaces. The measurement accuracy of the width and height is \pm 5 $\mu \mathrm{m}$ and $\pm 3 \mu \mathrm{m}$, respectively. The measurement repeatability of the width and height is 0.5 $\mu \mathrm{m}$ and $1 \mu \mathrm{m}$, respectively. This enables the joint surface to be measured at a high data density $(1024 \times 768$ pixels per image). The sampling interval for the objective surfaces is accurate up to $25 \mu \mathrm{m}$. Compared to the sampling resolution of the laser scanner, optical profiler has higher accuracy and precision in the point position of the X-Y coordinates and height measurement.

Compression and shear tests were carried out using a servo-controlled apparatus, which includes a compression unit, shear unit, and an automatically recording feedback system. The specimens of the jointed rock were fixed into the upper and lower shear boxes. Then, the vertical force was loaded by load cells, MTS MODEL. The horizontal load was applied by shear cells, TCLU. The displacements were measured by recording cells with electric gap sensors, HA-162S-9108. During the shear process, the upper surface moves 
along a single joint and the contact area decreases as the shearing process advances. The reduction of shear area is calculated in the feedback system according to the shear rate and the moved displacement. Then, the normal load is automatically decreased with the reduction of the contact area to maintain a constant normal confining stress.

\section{Test Results}

\section{Distribution of Parameter $Z_{2}$ on Entire Joint Surface}

The root mean square first derivation $\left(Z_{2}\right)$ is related to the roughness slope and can be used to predict the friction of the surface (Myers 1962). It is one of the optimal slope parameters for evaluating the joint roughness coefficient $(J R C)$ values from the profiling lines (Kishida and Tsuno 2001; Li and Zhang 2015; Mo and Li 2019). This characteristic refers to the cumulative inclination of the surface roughness along one profile line. The formula is expressed as

$$
Z_{2}=\left[\frac{1}{M-1} \sum_{i=1}^{M-1}\left(\frac{\Delta y}{\Delta x}\right)_{i}^{2}\right]^{\frac{1}{2}}
$$

where $M$ represents the profiling points along the lines, $\Delta y$ is the height difference between two adjacent points, and $\Delta x$ is the interval of profiling points.

In the past, one or several profiles were employed to evaluate the $Z_{2}$ value of the fresh fracture surface. However, it is still a challenging task to select the typical profile lines from the entire joint surface. In order to determine the appropriate profile lines, the distribution of parameter $Z_{2}$ on the entire joint surface was investigated in the present study. In the profiling process, the fresh joint surface of specimen G1 was measured by two profiling techniques (laser scanner and optical profiler). The entire surface was profiled with 475 lines at the length of $120 \mathrm{~mm}$. The $Z_{2}$ value of each profile line was 
212 calculated at a sampling space of $0.25 \mathrm{~mm}$. These values at the length of the specimen of

$213120 \mathrm{~mm}$ are shown in Fig. 3. The mean $Z_{2}$ represents the average $Z_{2}$ value of all the 214 profiles. Parameter Stdev is the standard deviation that represents the dispersion degree 215 of all the $Z_{2}$ values. There is obvious dispersion among the $Z_{2}$ values on the entire lower 216 and upper joint surfaces. Previous studies have stated that one or several profiles could 217 estimate the $J R C$ value. However, as shown in Fig. 3, the variation in $Z_{2}$ values along the different profiled lines results in different degrees of roughness. Therefore, an arbitrary profile may overestimate or underestimate the joint roughness. Meanwhile, due to the dispersion of the $Z_{2}$ values at this sampling interval, it is an overwhelming challenge to try to select the typical profile lines or the representative lines from a natural fracture surface. Rather than using a few selected typical lines on the joint surface, the use of all the geometric features of the entire joint surface is more appropriate for sufficiently evaluating the JRC values (Gentier et al. 2000; Belem et al. 2000; Grasselli 2006; Wang et al. 2019). In the present study, in contrast to the $Z_{2}$ value of one specific profile line, the mean $Z_{2}$ value of all the profiles is more stable and reasonable for representing the joint roughness. It can take into consideration the morphology of the entire joint surface. The influence of two kinds of profiling techniques was discussed by comparing the $Z_{2}$ values measured from the laser scanner (Figs. 3(a) and (b)) and optical profiler (Figs. 3(c) and (d)). The apparent difference in $Z_{2}$ values between the two kinds of profiling data is caused by the different accuracy and precision of profiling techniques. The results of the comparison demonstrate that the mean $Z_{2}$ values of the upper and lower surfaces calculated with the optical profiler data are closer than those calculated with the laser scanner. This proves that optical profiler accurately records the geometrical characteristic of fresh upper and lower surfaces since the fresh upper and lower surfaces are inversions 
with each other, and the similarity of roughness between upper and lower surfaces is realistically revealed by the optical profiler with high accuracy. Moreover, the standard deviation computed by the optical profiler is smaller than that computed by the laser scanner, which indicates that the $Z_{2}$ values are closer to the average value. Namely, using a measuring instrument with high precision can decrease the dispersion degree of the $Z_{2}$ values. The mean $Z_{2}$ values measured from the optical profiler are smaller than measured from the laser scanner. This is because the optical profiler has high precision that leads to more concentrated $Z_{2}$ values than the laser scanner. In addition, the smaller standard 
joint surface. The parameter of mean $Z_{2}$ is sensitive to the sampling interval. Their values decrease with an increasing sampling distance. The corresponding relationship between the parameter of mean $Z_{2}$ and $J R C$ is examined in the next section.

\section{Mean Parameter $Z_{2}$ in JRC Evaluation}

The $J R C$ values can be evaluated by $Z_{2}$ values from the relationships between the roughness degree and the surface characteristics. Previously, several linear relationships (Yu and Vayssade 1991) and power-law relationships (Tatone and Grasselli 2010; Jang et al. 2014; Li and Zhang 2015) were proposed. In addition, these relationships were modified by taking into account the specific characteristics of $Z_{2}$ such as the shear direction (Zhang et al. 2014; Wang et al. 2019) and the asperity orders (Liu et al. 2017). However, these studies were mainly conducted based on one or several random profiles. In the present study, the mean $Z_{2}$ values of all the profiles were adopted to evaluate the $J R C$ values of the fresh joint surface. The feasibility was examined by the linear relationships (Yu and Vayssade 1991) and power-law relationships (Tatone and Grasselli 2010), respectively. The linear relationships are given by Eqs. (2), (3), and (4). The powerlaw relationships are given by Eqs. (5) and (6).

The $J R C$ values were estimated by linear relationships in three sampling intervals 
evaluated $J R C$ values were compared with the $J R C$ values calculated from the BartonBandies model (Barton and Choubey 1977). In this study, the JRC values calculated by the backward analytical method are defined as the definitional JRC values. In order to obtain the definitional JRC values, a direct shear test was conducted on a granite specimen and the peak shear strength was measured. The empirical equation to calculate the definitional $J R C$ is given as follows:

$$
J R C=\frac{\tan ^{-1}\left(\tau / \sigma_{n}\right)-\Phi_{b}}{\log _{10}\left(J C S / \sigma_{n}\right)}
$$

where $\tau$ is the peak shear strength of the joint, $\sigma_{n}$ is the normal stress, $\Phi_{b}$ is the basic friction angle that can be substituted for the residual friction angle, and JCS is the joint wall compressive strength that is equal to the unconfined compression strength. For the weathered specimen, the JCS values are equal to $1 / 4$ of the compressive strength according to the degradation alteration theory of Barton (Barton and Choubey 1977). The comparison results for the $J R C$ values evaluated by the linear/power-law relationships and definitional JRC values are given in Table. 2.

At the sampling interval of $1.0 \mathrm{~mm}$, the $J R C$ values estimated by both linear and power-law relationships agree well with the definitional JRC values. The most likely reason is that this interval level can map the "waviness" of the joint surface. The standard profiles recommended by ISRM (1985) are scanned at this interval level to assess the degree of roughness. Meanwhile, the present study also proves that the parameter of mean $Z_{2}$ is suitable as the quantitative index for evaluating the $J R C$ values with a sampling interval of $1.0 \mathrm{~mm}$.

As shown in Table 2, although both relationships can approximately estimate the $J R C$ at the $1.0 \mathrm{~mm}$ scale, the deviations between the $J R C$ values evaluated only by the 
power-law relationship and those evaluated by definitional $J R C$ values are less than $\pm 5 \%$.

These deviations are acceptable according to previous studies (Jang et al. 2014). Thus, the power-law relationship was applied to calculate the $J R C$ values in the following work for distinguishing the pre- and post-sheared surfaces.

\section{Experimental Results of Repeated Shear Tests}

In terms of the loading conditions, Barton (1973) predicted the peak shear strength of rock joints under the normal stress range (normal stress ratio of $\sigma_{n} / J C S=0.01-0.3$ ) using the Barton-Bandies model. Afterward, Grasselli and Egger (2003) further pointed out that the failure of the roughness asperities initiates at low stress $\left(\sigma_{n} / J C S=0.015\right)$. In this study, by setting the normal stress at $3 \mathrm{MPa}$, shear tests were conducted under a normal stress ratio of $\sigma_{n} / J C S=0.02$ and a constant shear rate of $0.1 \mathrm{~mm} / \mathrm{min}$, which is within the standardized shear rate of 0.02 to $0.2 \mathrm{~mm} / \mathrm{min}$ (ISRM 1985).

Under the above-mentioned conditions, repeated shear tests were performed to investigate the alteration of the joint surfaces. Then, the effects of surface roughness on the shear strength were examined. The specimens (G1 and G2) were tested under constant normal loading until the residual state; and subsequently, they were repositioned to their initial positions and tested again. Namely, direct shear tests were performed two times.

Fig. 5 shows the shear stress-shear displacement relations of the direct shear experiments conducted on granite specimens G1 and G2. A great drop in peak shear strength was observed from the first shear process to the second shear process. It is most likely that the change in the roughness of the surface is responsible for the reduction in shear strength. Hence, clarification of the roughness between the pre- and post-sheared surfaces is of significance. A statistical parameter is required to distinguish these differences in surfaces while assessing the degree of roughness. 


\section{Distinguishing Pre- and Post-sheared joint surfaces}

In this section, the definitional JRC values were measured from the peak shear strength by Eq. (7), while the estimated $J R C$ values were calculated by the mean $Z_{2}$ parameter using the power-law relationship at the sampling interval of $1.0 \mathrm{~mm}$ by Eq. (6). The obtained results for the $J R C$ values are shown in Table. 3. As shown in this table, for the initial joint surfaces (Case-1), the definitional JRC values of the lower and upper surfaces could be estimated by the mean $Z_{2}$ value at the sampling interval of $1.0 \mathrm{~mm}$. However, for the sheared joint surfaces (Case-2), the mean $Z_{2}$ values significantly overestimate the definitional JRC values of two surfaces. Between the estimated JRC values in the initial and sheared surfaces, no great difference is observed, especially for on the intervals of $0.25 \mathrm{~mm}$ to $2.0 \mathrm{~mm}$ and did not discuss smaller intervals sufficiently. specimen G2. Instead of the prominent reduction of definitional JRC (or shear strength), only a slight change of surface geometry is exhibited with mean $Z_{2}$ value at this profiling magnitude. The reasons most expected for the misestimating are the over-wide sampling interval and the limitation of the average parameter. The following section discussed the effect of sampling interval and statistical parameter on distinguishing fresh and sheared joint surfaces.

The interval of $1.0 \mathrm{~mm}$ is only able to capture the relative large-scale characteristics of the local points (e.g., waviness asperities) of a fracture surface, while it cannot capture the small-scale asperities (e.g., unevenness asperities) that are smaller than this sampling level. Thus, the interval of $1.0 \mathrm{~mm}$ is unable to grasp the slight changes in the geometrical surface, and a smaller sampling scale must be employed. On the other hand, $Z_{2}$ is sensitive to the sampling interval (Lee et al. 2001; Jang et al. 2014). Previous researches focused Thus, the joint surface is profiled here under the interval range of $0.025 \mathrm{~mm}$ to $0.1 \mathrm{~mm}$ 
using optical profiler, which has high resolution. The calculated results for the mean $Z_{2}$ values of the two specimens, G1 and G2, are plotted in Fig. 6.

It is clear from Fig. 6 that the mean $Z_{2}$ values of both specimens strongly depend on the sampling intervals and decrease as the sampling interval increases. Moreover, the difference of mean $Z_{2}$ values between the initial surfaces and the sheared surfaces becomes pronounced with decreased intervals (Case- 1 is the initial surface and Case- 2 is the sheared surface). The smaller sampling intervals were confirmed helpful to detect the subtle alteration of surface geometry according to the observed different mean $Z_{2}$ values in Fig. 6 (a). However, a great reduction in the mean $Z_{2}$ values for the pre- and postsheared surfaces is only observed in specimen G1. In specimen $G 2$, the mean $Z_{2}$ values show no remarkable drop after the shear process, and even a slight rise occurs in the upper surface with small intervals. In general terms, the surface roughness was observed to progressively decreased with the shear process (Lee et al. 2001; Belem et al. 2009; Ge et al. 2017). Here, the increasing trend of the mean $Z_{2}$ parameter contradicts the decreasing of surface roughness with the shear process in specimen G2 of Fig. 6 (b). It may be attributed to the disadvantage of the mean $Z_{2}$ parameter for completely distinguishing the joint surfaces before and after shearing.

The $Z_{2}$ value only represents the cumulative inclination of surface roughness along with a profile and ignores the variation in the distribution of the apparent dip angles on the joint surfaces. Park et al. (2013) claimed that the distribution of the apparent dip angles aids in the understanding of the roughness mobilization within the joint surfaces. In our study, the apparent dip angles of the surface asperity were measured with a highresolution instrument and analyzed. Fig. 7 presents the frequency distribution of the apparent dip angles on specimens G1 and G2 with the sampling intervals of $0.025,0.1$ 
$\mathrm{mm}$, and $1.0 \mathrm{~mm}$. The total slope angles were sorted and cumulated at $2^{\circ}$. For both initial and sheared surfaces, bell-shaped distributions are exhibited and located approximately symmetrically around $0^{\circ}$. For the two specimens, in contrast with the results of the sampling scale of $1.0 \mathrm{~mm}$ (Figs. 7(a) and (d)), variations in the distributions due to shearing are observed with the small sampling intervals of $0.1 \mathrm{~mm}$ and $0.025 \mathrm{~mm}$ (Fig. 7(b) and (e), and (c) and (f)). This implies that changes in the distribution of the slope angles existed under this normal loading stress and that these changes in small-scale roughness are only captured with small sampling scales. As illustrated in Fig. 7, when the small sampling intervals of $0.025 \mathrm{~mm}$ and $0.1 \mathrm{~mm}$ are applied, after the shear process, the proportion of larger slope angles $\left(-90^{\circ} \sim-30^{\circ}\right.$ and $\left.30^{\circ} \sim 90^{\circ}\right)$ decreases and the frequency density of small slope angles $\left(-10^{\circ} \sim 0^{\circ}\right.$ and $\left.0^{\circ} \sim 10^{\circ}\right)$ increases. Namely, the rough asperities with larger slope angles are shaved to the smooth asperities with smaller slope angles after the shear test.

During the shear test, only the inclination angles leaning in the shear direction should be considered as contributing to the resistance. In the present study, these slope angles are defined as active slope angles. Here, the distribution of active angles is adopted to characterize the surface alteration quantitatively. As an example, the proportion of the active slope angles of specimens G1 and G2 are analyzed with the interval of $0.1 \mathrm{~mm}$ and the results are given in Fig. 8. Each column shows the corresponding slope angles at a particular sampling angle $\left(2^{\circ}\right)$. The probability density function (PDF) of the Gaussian distribution was adopted to fit the distribution of apparent dip angles. The coefficient of determination $R^{2}$ was used to represent the goodness of fit. The probability density function $f(x)$ is given as: 


$$
f(x)=\frac{1}{C_{s} \sqrt{2 \pi}} e^{-\frac{x^{2}}{2 C_{s}}}
$$

where $C_{s}$ is the standard deviation, $x$ is the variable of slope angle leaning in the shear direction.

From the results of the regression, the PDF corresponds well with the proportion of active slope angles. The distribution of smaller and larger slope angles is captured by the fitted line, and the changes in slope angles in the pre- and post-sheared surfaces are readily characterized by the curve of PDF. The standard deviation of the probability distribution of the active slope angles was employed as the characteristic index $\left(C_{s}\right)$. As shown in Fig. $\mathbf{8}$, the reduction of the probability in larger slope angles and the increase of the probability in smaller slope angles are consistent with the decreasing trend of standard deviation in PDF. Consequently, the characteristic index $\left(C_{s}\right)$ can clarify the initial surface and the sheared surface for the two specimens. The pre- and post-surfaces of specimen G2 are also distinguished by different values for this index, while the parameter of mean $Z_{2}$ cannot clarify the difference in the two surfaces in specimen G2. In addition, the reduction of the index $\left(C_{s}\right)$ corresponds to the decrease of surface roughness. This suggests that the roughness alteration induced by the shear process can be properly characterized by the parameter $\left(C_{s}\right)$.

The changes in the quantified index $\left(C_{S}\right)$ in the pre- and post-sheared surfaces with different sampling intervals are plotted in Fig. 9. The sampling interval greatly influences the changes in slope angles. With the reduction in the sampling interval, the discrepancy of $C_{s}$ between the initial and sheared surfaces becomes more prominent. Hence, small sampling intervals are also essential for capturing the asperity alteration. Moreover, it is suggested from Fig. 9 that, with sampling intervals of less than $0.1 \mathrm{~mm}$, the initial and 
sheared surfaces can be distinguished by incorporating quantified index $C_{S}$.

Thus, the distribution of slope angles is helpful for distinguishing the pre- and postsheared surfaces. Simultaneously, the appropriate magnitude of the sampling interval is necessary for capturing the surface alteration. Specifically, small sampling scales $(<=0.1$ $\mathrm{mm}$ ) are confirmed as available for recording the micro characteristics during the shear process. Overall, the incorporation of the distribution of slope angles and small sampling intervals $(<=0.1 \mathrm{~mm})$ is useful for detecting the roughness evolution of joint rock surfaces.

\section{Numerical simulation}

In order to further examine the effects of a slight change in surface geometry on the shear behavior of rock joints, the mechanical shear model proposed by Kishida and Tsuno (2001) was adopted to simulate the repeated shear tests with the profile data obtained from different sampling intervals. The whole joint surfaces of specimen G1 and G2 were profiled by optical profiler and digitized into the point cloud. Then, the digital morphology data were input into the mechanical shear model to replicate the evolution of shear stress during shear processes. In addition, the influence of the sampling scales on the prediction of the shear behavior by numerical simulation was discussed.

The mechanical shear model utilizes the profiled data of the geometric surface to simulate the variation of shear stress in the entire shear process. The applicability has been validated by the previous studies (Kishida et al. 2011; Kishida and Sakurai 2007). The mechanical shear model is developed on the concept that the shear stress of rock joints is governed by the friction and the degradation of the asperities. The outline of the mechanical shear model is briefly interpreted. Fig.10 shows the concept of stress on the extracted contact asperities or contact points. The effective normal stress $\sigma^{\prime}$ and 
447 effective shear stress $\tau^{\prime}$ act on the contact points can be separated into horizontal stress

448

$Q$ and vertical stress $P$ on the rock joint. The stress $P$ and $Q$ following the equilibrium for the joint is $Q-\operatorname{Ptan} \phi_{b}=0$. Here, $\phi_{b}$ is the basic frictional angle.

Fig.11 illustrates the procedures for implementing the mechanical shear model as below:

i. The dilation angle was firstly assumed and the upper surface will slide along the assumed angle in the shearing process.

ii. In the initial shear state, when the asperity angle is larger than the assumed angle, these asperities are determined as the contact asperities. The number of contact asperities is counted in the joint interface.

iii. The shear stress and the normal stress applying to the contact asperities are calculated. Then, the concentrated stress on the rock joint surface is obtained and compared with the uniaxial compressive strength.

iv. The asperities with larger slope angles are shaved when the concentrated stress larger than the uniaxial compressive strength. Then, the asperities with smaller angles are contacted. The contacted asperities increase, and the concentrated stress at each asperity reduces.

v. Until the concentrated stress becomes smaller than the uniaxial compressive stress, the specimen slides along contacted asperities at one determined dilation angle in the final shear state.

Hence, the shear behavior of rock joints, whereby the shear stress increases, reaches the peak stress, decreases (strain softening), and then gradually arrives at the residual state, could be systematically expressed by the model. The detail of the employed model has been reported in the previous study (Kishida and Sakurai 2007).

Here, the digital data with the sampling intervals of $0.1 \mathrm{~mm}, 0.5 \mathrm{~mm}$, and $1.0 \mathrm{~mm}$ 
for specimens G1 and G2 were applied to the mechanical shear model. The evolution of shear stress was calculated in three cases with each interval. The simulation and experimental results for the first and second shear processes were compared in order to examine the effects of the joint surface geometry and sampling scales. Fig. 12 shows these simulation and experimental results for the first and the second shear processes. It needs to be noted that the simulation focuses on depicting the process of shear stress from the early stage to the final residual stage, while the slight rise and fall in shear stress during the residual shear state is not the object of this experimental work.

With an interval of $0.1 \mathrm{~mm}$, the simulation results show a good agreement with the measured shear behavior of the two specimens. In this case, based on the profiled data, the peak shear strength and residual shear strength during both the first and second shear processes are replicated well. Meanwhile, the simulated results with the sampling intervals of $0.5 \mathrm{~mm}$ and $1.0 \mathrm{~mm}$ misestimate the evolution of shear stress in the first and second shear processes. In the first shear process, Figs. 12(a) and (c) show that the model predictions underestimate the peak shear stress of specimens G1 and G2. Due to these large sampling scales, only the "waviness" components might be captured. Some critical parts of the small scale roughness were omitted and this led to the absence of the resistance contributed by these neglected components. In the second shear process, illustrated in Figs. 12(b) and (d), the simulated results overestimate or underestimate the residual shear stress and peak shear displacement with the sampling intervals of $0.5 \mathrm{~mm}$ and $1.0 \mathrm{~mm}$. One possible reason is that, although the micro-roughness is shaved and the resistance derived from the unevenness disappears after the first shear process, these changes cannot be sufficiently reflected in the simulation of the second shear process. Hence, the proper sampling interval is vital to capturing the small-scale roughness in the 
simulation procedure.

In addition, a significant decrease in peak shear stress from the first shear process to the second shear process can be apparently observed with the interval of $0.1 \mathrm{~mm}$ from the simulation results. The expectable reason is the sampling interval of $0.1 \mathrm{~mm}$ has the capacity to capture both the "waviness" and the "unevenness" of a fracture surface. Meanwhile, the simulated reduction in shear strength between the two shear processes is ambiguous compared to the actual behavior when applying the sampling intervals of 0.5 $\mathrm{mm}$ and $1.0 \mathrm{~mm}$, especially for specimen G1. This may be resulted from these larger interval levels only profiling the "waviness" asperities. According to the previous study, the second order asperities control the cyclic shear behavior (Lee et al. 2001), the degradation of "unevenness" asperities on joint surfaces should dominantly affect the evolution of shear stress. Thus, in the simulation case of the larger sampling interval, the drastic drop of shear strength in the repeated shear process was not detected because the "unevenness" asperities on the surface were omitted and the subsequent occurrence of shear stress was predicted roughly. Conversely, the small sampling interval captures the change of "unevenness" asperities in the repeated shear process, and correctly present the shear stress from the micro-contact asperities.

\section{Conclusion}

This study has attempted to distinguish the pre- and post-sheared surfaces of natural granite joints through analyses of the distribution of $Z_{2}$ values and the distribution of slope angles on joints surfaces at various sampling intervals. From the observed dispersion of the $Z_{2}$ values on the joint surfaces, it was implied that utilizing the $Z_{2}$ values of one specific profile may bring about the misestimation of the roughness of the joint surfaces, especially with small sampling intervals. The $J R C$ values estimated from the mean $Z_{2}$ 
values at the sampling interval $1.0 \mathrm{~mm}$ coincided well with the definitional $J R C$ values and suggests its reasonability for expressing the roughness of the fresh joint surface. However, it was demonstrated that the above method may greatly misestimate the JRC values of the sheared joint surfaces because it only represents the cumulative inclination of the whole joint surface and ignores the variation in the distribution of apparent dip angles. Actually, the change in surface roughness through the shear process could be distinguished by the mean $Z_{2}$ values on specimen $G 1$, which has a non-uniform distribution of slope angles, while the change could not be distinguished in the case of specimen G2 with evenly distributed slope angles. roughness mobilization with small sampling intervals $(<=0.1 \mathrm{~mm})$, and the standard deviation of the probability distribution of the active slope angles was adopted as one interval of $0.1 \mathrm{~mm}$ between the first and second shear processes. The above comparison illustrates that the "unevenness" asperities captured by the sampling scale of $0.1 \mathrm{~mm}$ have 
$\mathrm{mm}$ did the simulation results show a good agreement with the experimental results. It was demonstrated the sampling interval in this magnitude sufficiently maps the surface asperities and secures the accuracy of numerical prediction for the mechanical response in the rock joints observed in the repeated shear cycles.

Overall, it can be concluded that the well-known statistical parameter of the mean $Z_{2}$ values cannot enough distinguish the pre- and post-sheared surfaces, especially the initial surface with evenly distributed slope angles, while a characteristic index based on the distribution of slope angles should be valid. In addition, the small sampling interval $(<=0.1 \mathrm{~mm})$ is strongly recommended for measuring the surface roughness since they enable the "waviness" and "unevenness" of a fracture surface to be profiled and the alteration of the apparent dip angles to be captured.

\section{Data Availability Statement}

All profiled roughness data during the study are available from the corresponding author by request.

\section{Acknowledgements}

The first author was financially supported by the Japanese Government (MEXT) Scholarship and the Chinese Scholarship Council.

\section{References}

Asadollahi, P., and Tonon, F. 2010. “Constitutive model for rock fractures: Revisiting Barton’s empirical model.” Eng. Geol. 113 (1-4), 11-32. http://doi.org/10.1016/j.enggeo.2010.01.007.

Barton, N. 1973. "Review of a new shear-strength criterion for rock joints." Eng. Geol. 7 (4), 287-332. 
http://doi.org/10.1016/0013-7952(73)90013-6.

Barton, N. 1976. “The shear strength of rock and rock joints.” Int. J. Rock Mech. Min. Sci. 13 (9), 255-279. http://doi.org/10.1016/0148-9062(76)90003-6.

Barton, N., and Choubey, V. 1977. "The shear strength of rock joints in theory and practice.” Rock Mech. 10 (1-2), 1-54. http://doi.org/10.1007/BF01261801.

Belem, T., Homand-Etienne, F., and Souley, M. 2000. "Quantitative parameters for rock joint surface roughness.” Rock Mech. Rock Eng. 33 (4), 217-242. http://doi.org/10.1007/s006030070001.

Belem, T., Souley, M., and Homand, F. 2009. "Method for quantification of wear of sheared joint walls based on surface morphology." Rock Mech. Rock Eng. 42(6), 883-910. https://doi.org/10.1007/s00603-008-0023-z

Byerlee, J. D. 1978. "Friction of rocks." Pure Appl. Geophys. 116 (4-5), 615-626. http://doi.org/10.1007/BF00876528.

Ge, Y., Tang, H., Eldin, M. A. M. E., Wang, L., Wu, Q., and Xiong, C. 2017. "Evolution process of natural rock joint roughness during direct shear tests." Int. J. Geomech. 17 (5), E4016013. http://doi.org/10.1061/(ASCE)GM.1943-5622.0000694.

Gentier, S., Riss, J., Archambault, G., Flamand, R., and Hopkins, D. 2000. “Influence of fracture geometry on shear behavior.” Int. J. Rock Mech. Min. Sci. 37 (1-2), 161-174. http://doi.org/10.1016/S13651609(99)00096-9.

Grasselli, G. 2006. "Manuel eocha medal recipient shear strength of rock joints based on quantified surface description.” Rock Mech. Rock Eng. http://doi.org/10.1007/s00603-006-0100-0.

Grasselli, G., and Egger, P. 2003. "Constitutive law for the shear strength of rock joints based on threedimensional surface parameters." Int. J. Rock Mech. Min. Sci. 40 (1), 25-40. http://doi.org/10.1016/S1365-1609(02)00101-6.

Grasselli, G., Wirth, J., and Egger, P. 2002. “Quantitative three-dimensional description of a rough surface and parameter evolution with shearing." Int. J. Rock Mech. Min. Sci. 39 (6), 789-800. http://doi.org/10.1016/S1365-1609(02)00070-9.

Hong, E. S., Kwon, T. H., Song, K. Il, and Cho, G. C. 2016. “Observation of the degradation characteristics and scale of unevenness on three-dimensional artificial rock joint surfaces subjected to shear." Rock Mech. Rock Eng. 49 (1), 3-17. http://doi.org/10.1007/s00603-015-0725-y. 
ISRM. 1985. "Suggested methods for the quantitative description of discontinuities in rock masses." Int. J. Rock Mech. Min. Sci. 15, 319-368. http://doi.org/10.1016/0148-9062(79)91476-1.

Jang, H. S., Kang, S. S., and Jang, B. A. 2014. "Determination of joint roughness coefficients using roughness parameters." Rock Mech. Rock Eng. 47 (6), 2061-2073. http://doi.org/10.1007/s00603013-0535-z.

Jiang, Q., Song, L., Yan, F., Liu, C., Yang, B., and Xiong, J. 2020. "Experimental investigation of anisotropic wear damage for natural joints under direct shearing test.” Int. J. Geomech. 20 (4), 1-18. http://doi.org/10.1061/(ASCE)GM.1943-5622.0001617.

Kishida, K., Kawaguchi, Y., Nakashima, S., and Yasuhara, H. (2011). "Estimation of shear strength recovery and permeability of single rock fractures in shear-hold-shear type direct shear tests." Int. J. Rock Mech. Min. Sci. 48(5), 782-793. http://dx.doi.org/10.1016/j.ijrmms.2011.04.002

Kishida, K., and Sakurai, Y. 2007. "Improvement of the mechanical shear model for rock joints considering the bearing effect." Soils and Foundations, 47(3), 613-628. https://doi.org/10.3208/sandf.47.613

Kishida, K., and Tsuno, K. 2001. The modeling of the shear behavior of rock joints in consideration of the material friction and the joint surface roughness." [In Japanese.] J Geotech Eng JSCE, 680(III-55), $245-261$

Kulatilake, P., Shou, G., Huang, T., and Morgan, R. 1995. "New peak shear strength criteria for anisotropic rock joints." Int. J. Rock Mech. Min. Sci. 32 (7), 673-697. http://doi.org/10.1016/01489062(95)00022-9.

Lee, H. S., Park, Y. J., Cho, T. F., and You, K. H. 2001. "Influence of asperity degradation on the mechanical behavior of rough rock joints under cyclic shear loading.” Int. J. Rock Mech. Min. Sci. 38 (7), 967-980. http://doi.org/10.1016/S1365-1609(01)00060-0.

Li, Y., and Zhang, Y. 2015. "Quantitative estimation of joint roughness coefficient using statistical parameters.” Int. J. Rock Mech. Min. Sci. 77, 27-35. http://doi.org/10.1016/j.jirmms.2015.03.016.

Liu, X. G., Zhu, W. C., Yu, Q. L., Chen, S. J., and Li, R. F. 2017. "Estimation of the joint roughness coefficient of rock joints by consideration of two-order asperity and its application in double-joint shear tests.” Eng. Geol. 220, 243-255. http://doi.org/10.1016/j.enggeo.2017.02.012.

Mo, P., and Li, Y. 2019. "Estimating the three-dimensional joint roughness coefficient value of rock fractures.” Bull. Eng. Geol. Environ. 78 (2), 857-866. http://doi.org/10.1007/s10064-017-1150-0. 
Myers, N. 1962. "Characterisation of surface roughness." Wear. 5 (3), 182-189. http://doi.org/10.1016/0043-1648(62)90002-9.

Myshkin, N. K., Petrokovets, M. I., and Chizhik, S. A. 1998. "Simulation of real contact in tribology." Tribol. Int. 31 (1-3), 79-86. http://doi.org/10.1016/S0301-679X(98)00010-3.

Park, J. W., Lee, Y. K., Song, J. J., and Choi, B. H. 2013. "A constitutive model for shear behavior of rock joints based on three-dimensional quantification of joint roughness.” Rock Mech. Rock Eng. 46 (6), 1513-1537. http://doi.org/10.1007/s00603-012-0365-4.

Plesha, M. E. 1987. "Constitutive models for rock discontinuities with dilatancy and surface degradation." International Journal for Numerical and Analytical Methods in Geomechanics, 11(4), 345-362. https://doi.org/10.1002/nag.1610110404

Reeves, M. J. 1985. “Rock surface roughness and frictional strength.” Int. J. Rock Mech. Min. Sci. 22 (6), 429-442. http://doi.org/10.1016/0148-9062(85)90007-5.

Renaud, S., Saichi, T., Bouaanani, N., Miquel, B., Quirion, M., and Rivard, P. 2019. "Roughness effects on the shear strength of concrete and rock joints in dams based on experimental data." Rock Mech. Rock Eng. 52 (10), 3867-3888. http://doi.org/10.1007/s00603-019-01803-x.

Sharifzadeh, M., Mitani, Y., and Esaki, T. 2008. "Rock joint surfaces measurement and analysis of aperture distribution under different normal and shear loading using GIS.” Rock Mech. Rock Eng. 41 (2), 299323. http://doi.org/10.1007/s00603-006-0115-6.

Tatone, B. S. A., and Grasselli, G. 2010. "A new 2D discontinuity roughness parameter and its correlation with JRC." Int. J. Rock Mech. Min. Sci. 47 (8), 1391-1400. http://doi.org/10.1016/j.ijrmms.2010.06.006.

Tatone, B. S. A., and Grasselli, G. 2013. "An investigation of discontinuity roughness scale dependency using high-resolution surface measurements." Rock Mech. Rock Eng. 46 (4), 657-681. http://doi.org/10.1007/s00603-012-0294-2.

Tse, R., and Cruden, D. M. 1979. "Estimating joint roughness coefficients." Int. J. Rock Mech. Min. Sci. 16 (5), 303-307. http://doi.org/10.1016/0148-9062(79)90241-9.

Wang, C., Wang, L., and Karakus, M. 2019. "A new spectral analysis method for determining the joint roughness coefficient of rock joints." Int. J. Rock Mech. Min. Sci. 113, 72-82. http://doi.org/10.1016/j.ijrmms.2018.11.009. 
Xia, C. C., Tang, Z. C., Xiao, W. M., and Song, Y. L. 2014. "New peak shear strength criterion of rock joints based on quantified surface description." Rock Mech. Rock Eng. 47 (2), 387-400. http://doi.org/10.1007/s00603-013-0395-6.

Yang, Z., Taghichian, A., and Li, W. C. 2010. "Effect of asperity order on the shear response of threedimensional joints by focusing on damage area.” Int. J. Rock Mech. Min. Sci. 47 (6), 1012-1026. http://doi.org/10.1016/j.jijmms.2010.05.008.

Yong, R., Ye, J., Li, B., and Du, S. G. 2018. "Determining the maximum sampling interval in rock joint roughness measurements using Fourier series.” Int. J. Rock Mech. Min. Sci. 101, 78-88. http://doi.org/10.1016/j.jirmms.2017.11.008.

Yu, X., and Vayssade, B. 1991. "Joint profiles and their roughness parameters." Int. J. Rock Mech. Min. Sci. 28 (4), 333-336. http://doi.org/10.1016/0148-9062(91)90598-G.

Zhang, G., Karakus, M., Tang, H., Ge, Y., and Zhang, L. 2014. "A new method estimating the 2D Joint Roughness Coefficient for discontinuity surfaces in rock masses.” Int. J. Rock Mech. Min. Sci. 72, 191-198. http://doi.org/10.1016/j.ijrmms.2014.09.009.

Zou, L., Li, B., Mo, Y., and Cvetkovic, V. 2019. "A high- resolution contact analysis of rough- walled crystalline rock.” Rock Mech. Rock Eng. 53 (5), 41-55. http://doi.org/10.1007/s00603-019-02034w. 


\section{Tables}

Table 1 Mechanical properties of employed samples

Table 2 Comparisons of $J R C$ values between evaluation by linear and power-law relationships and definitional calculation (Barton-Bandies model)

Table 3 Estimated $J R C$ and definitional $J R C$ of G1 and G2 in repeated shear tests 


\section{Tables}

Table 1 Mechanical properties of employed samples

\begin{tabular}{llll}
\hline $\begin{array}{l}\text { Specimen } \\
\text { No. }\end{array}$ & $\begin{array}{l}\text { Uniaxial } \\
\text { compressive } \\
\text { strength } \\
{[\mathrm{MPa}]}\end{array}$ & $\begin{array}{l}\text { Basic } \\
\text { friction } \\
\text { angle } \\
{\left[{ }^{\circ}\right]}\end{array}$ & $\begin{array}{l}\text { Normal } \\
\text { stiffness } \\
{[\mathrm{MPa} / \mathrm{mm}]}\end{array}$ \\
\hline G1 & 140.31 & 38.8 & 60.85 \\
G2 & 140.31 & 38.8 & 60.85 \\
G3 & 80.5 & 42.3 & 2.673 \\
G4 & 80.5 & 42.3 & 2.673 \\
\hline
\end{tabular}

Table 2 Comparisons of $J R C$ values between evaluation by linear and power law relationships and definitional calculation (Barton-Bandies model)

\begin{tabular}{|c|c|c|c|c|c|}
\hline $\begin{array}{l}\text { Specimen } \\
\text { No. }\end{array}$ & Relationships & $\begin{array}{l}J R C \\
\mathrm{SI}=0.25 \\
{[\mathrm{~mm}]}\end{array}$ & $\begin{array}{l}J R C \\
\mathrm{SI}=0.5 \\
{[\mathrm{~mm}]}\end{array}$ & $\begin{array}{l}J R C \\
\mathrm{SI}=1.0 \\
{[\mathrm{~mm}]}\end{array}$ & $\begin{array}{l}\text { Definitional } \\
J R C\end{array}$ \\
\hline \multirow{2}{*}{ G1 } & Linear & 29.94 & 20.73 & 17.12 & \multirow{2}{*}{16.15} \\
\hline & Power law & - & 19.18 & 16.63 & \\
\hline \multirow{2}{*}{$\mathrm{G} 2$} & Linear & 17.48 & 14.35 & 12.58 & \multirow{2}{*}{13.45} \\
\hline & Power law & & 14.23 & 12.58 & \\
\hline \multirow{2}{*}{ G3 } & Linear & 35.15 & 25.53 & 21.73 & \multirow{2}{*}{20.93} \\
\hline & Power law & - & 22.57 & 20.51 & \\
\hline \multirow{2}{*}{ G4 } & Linear & 33.65 & 21.61 & 18.61 & \multirow{2}{*}{18.81} \\
\hline & Power law & - & 19.83 & 17.91 & \\
\hline
\end{tabular}

Table 3 Estimated $J R C$ and definitional $J R C$ of G1 and G2 in repeated shear tests

\begin{tabular}{llllll}
\hline $\begin{array}{l}\text { Specimen } \\
\text { No. }\end{array}$ & Case & Normal stress & Estimated & Estimated & Definitional \\
& & $\sigma_{n}[\mathrm{MPa}]$ & JRC (Upper) & JRC (Lower) & JRC \\
\hline \multirow{2}{*}{ G1 } & Case-1 (Fresh) & 3 & 16.21 & 15.16 & 16.15 \\
& Case-2 (Sheared) & 3 & 13.51 & 13.47 & 8.53 \\
\multirow{2}{*}{ G2 } & Case-1 (Fresh) & 3 & 12.61 & 12.54 & 13.45 \\
& Case-2 (Sheared) & 3 & 13.45 & 11.22 & 3.84 \\
\hline
\end{tabular}




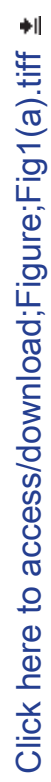

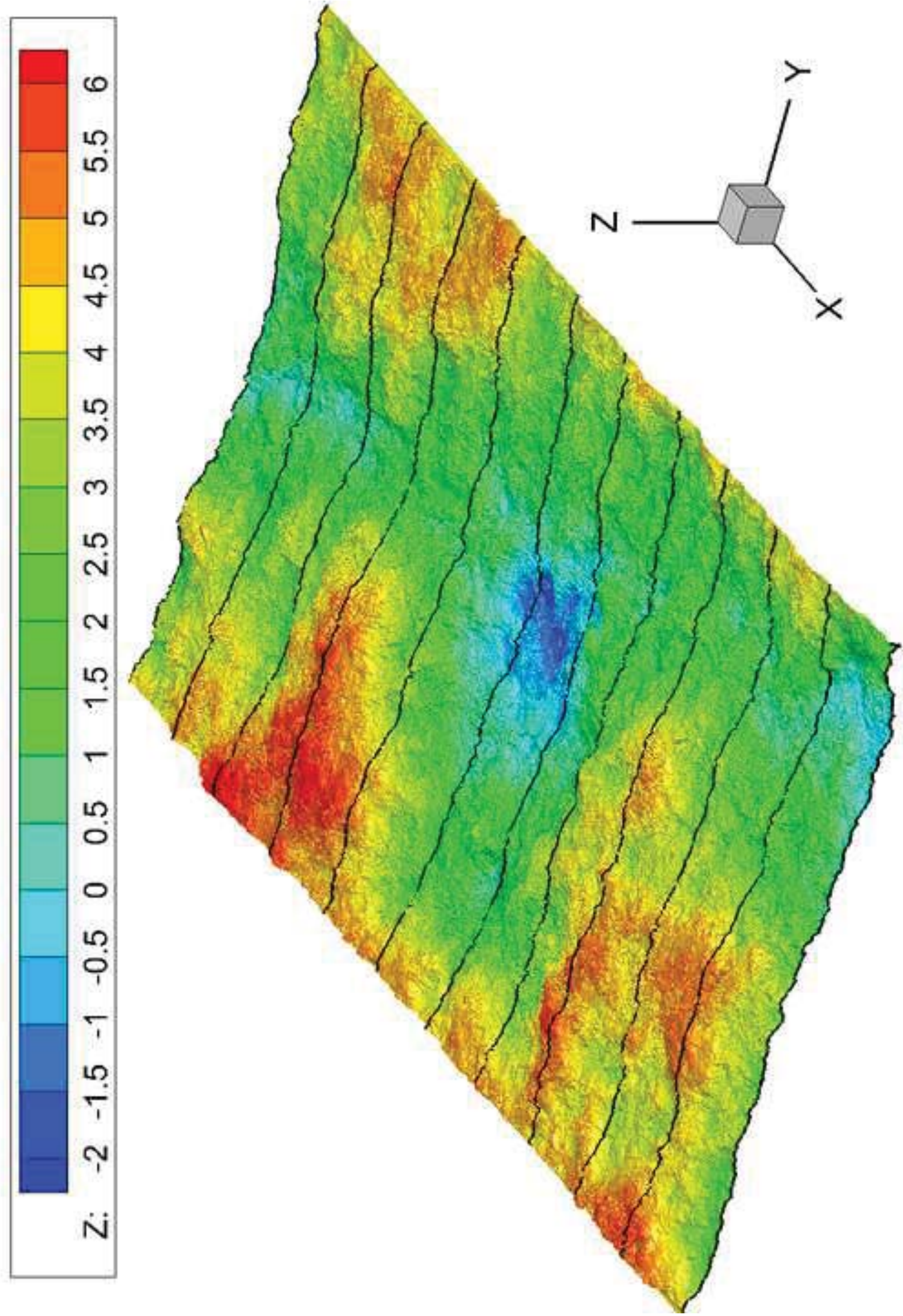




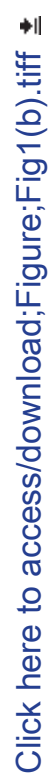

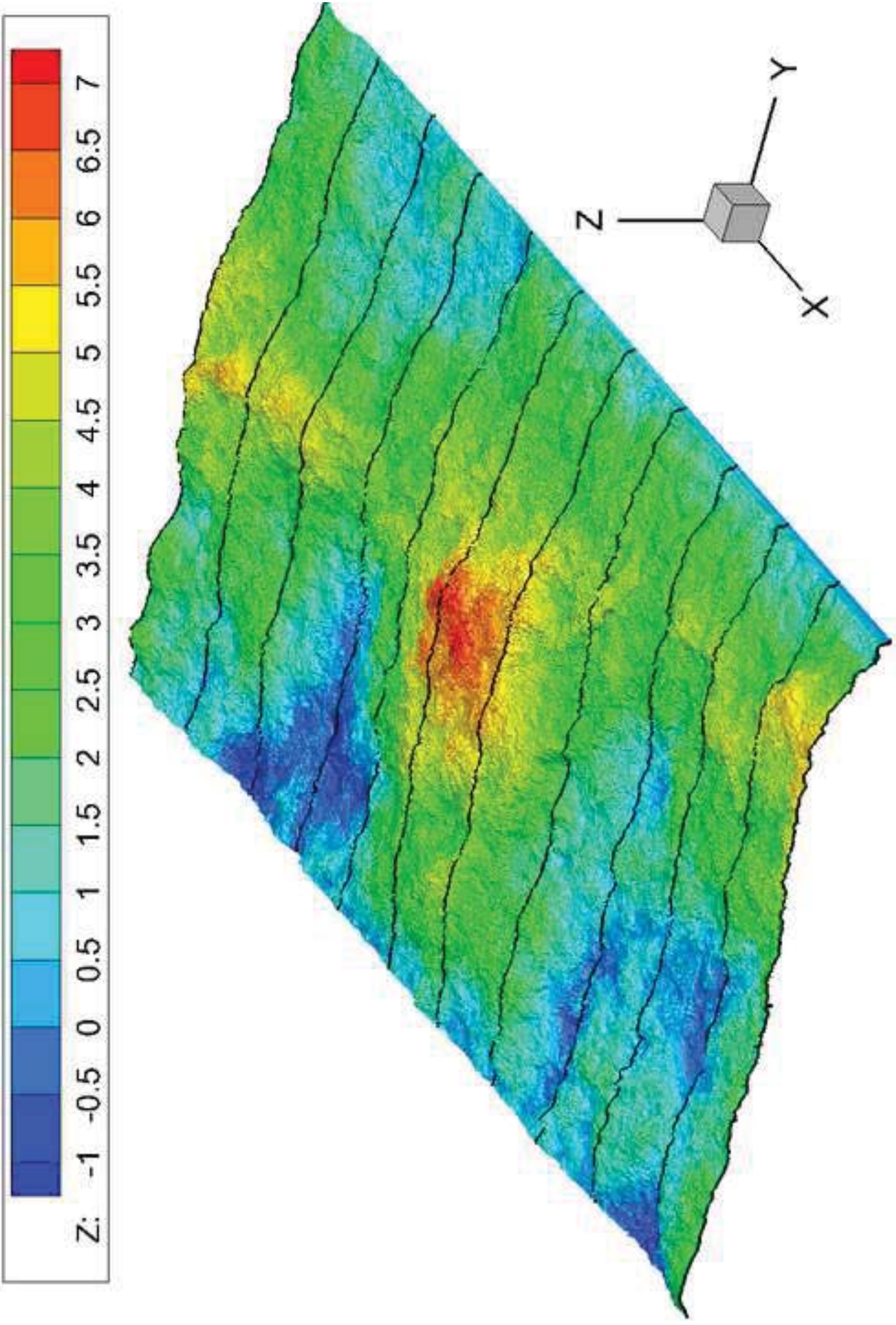




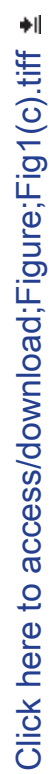
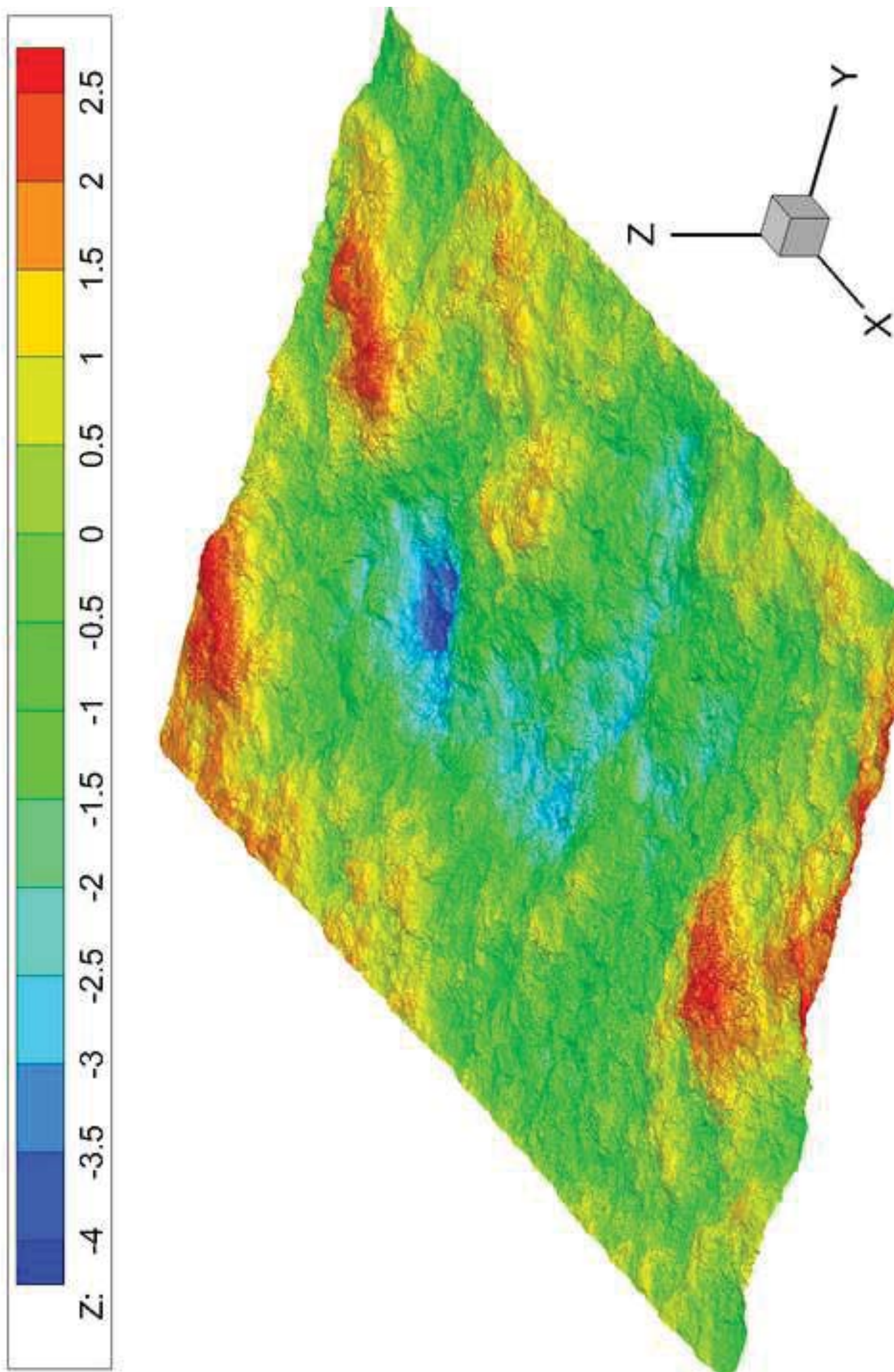


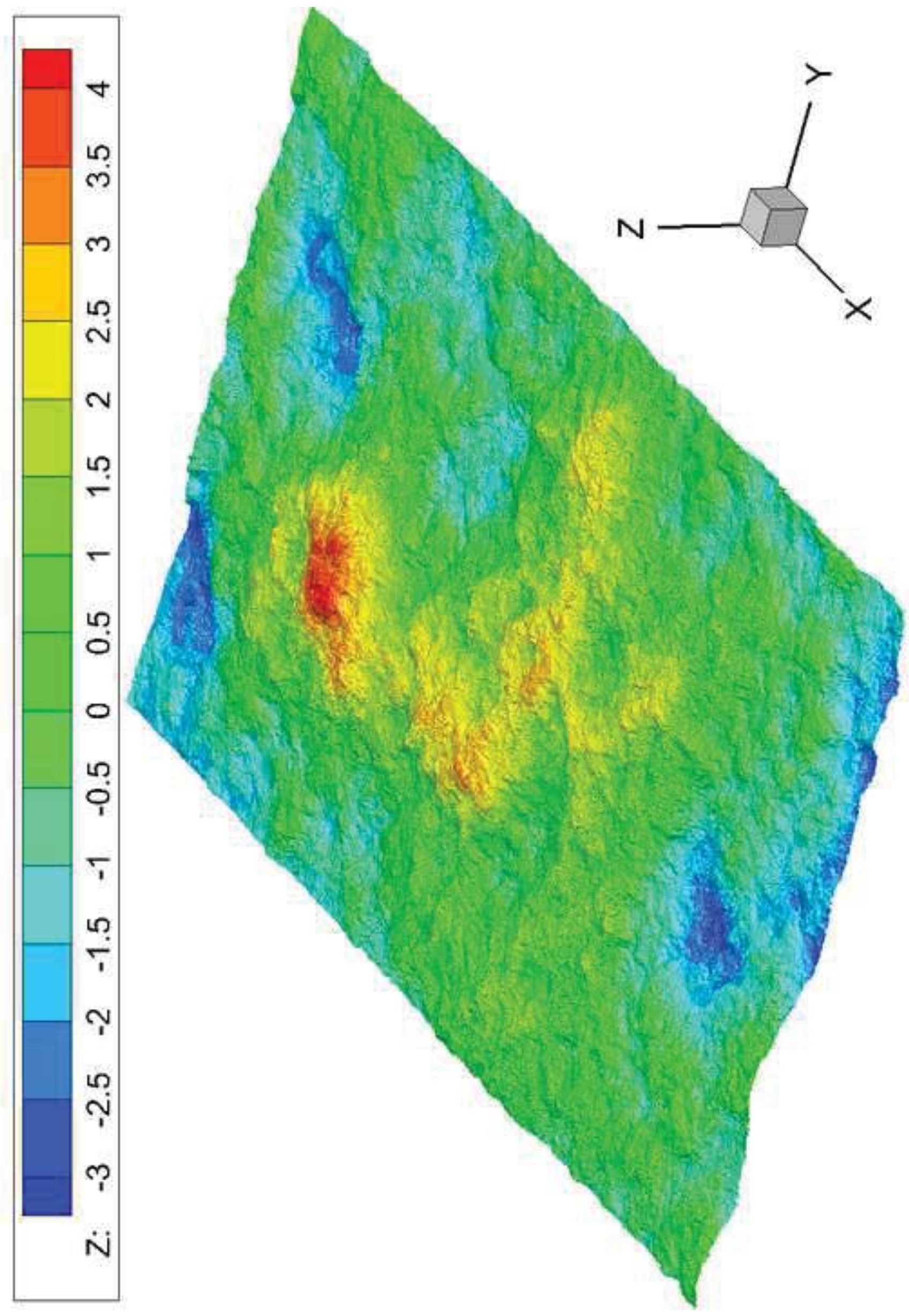




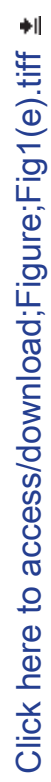
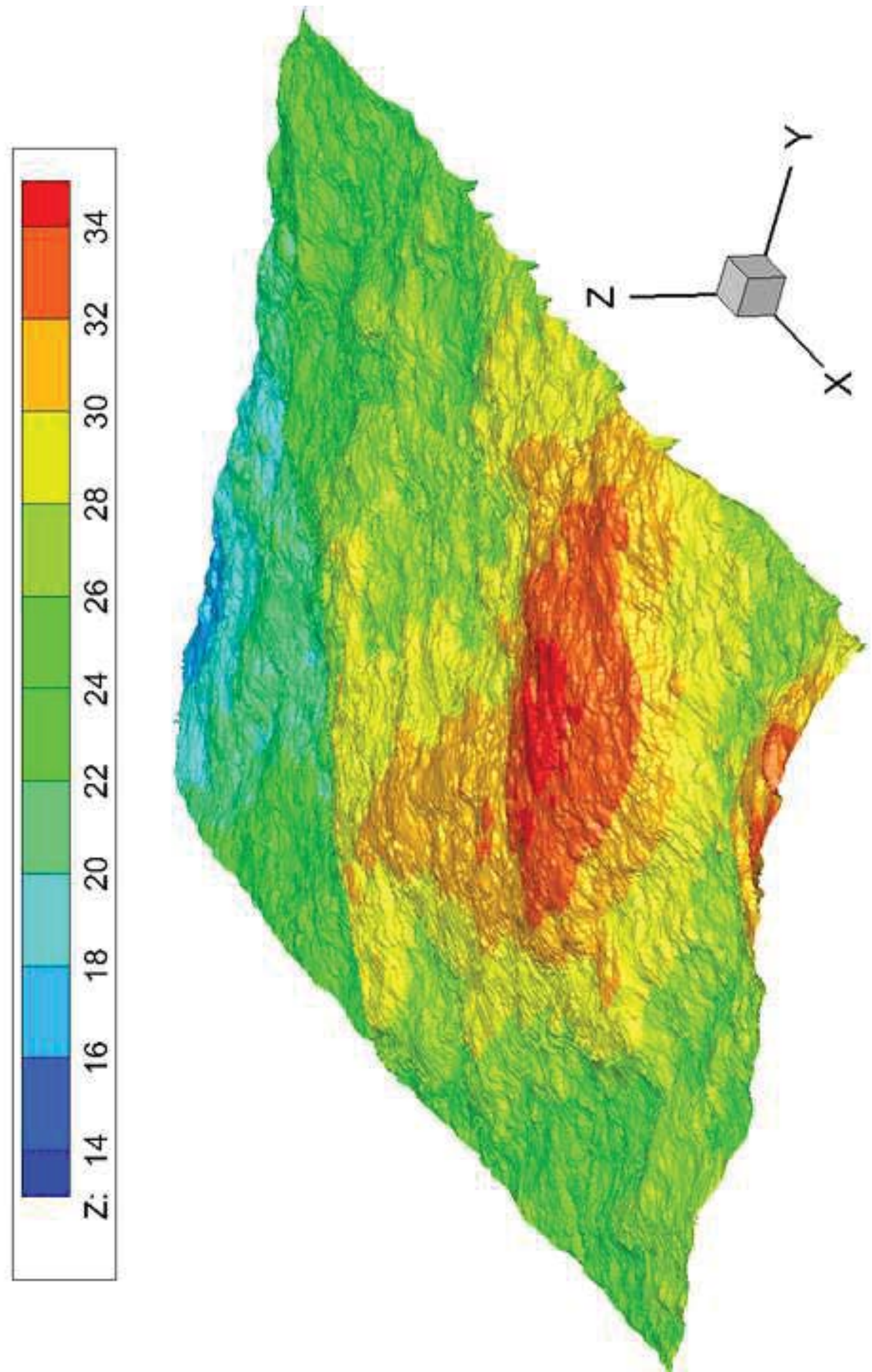


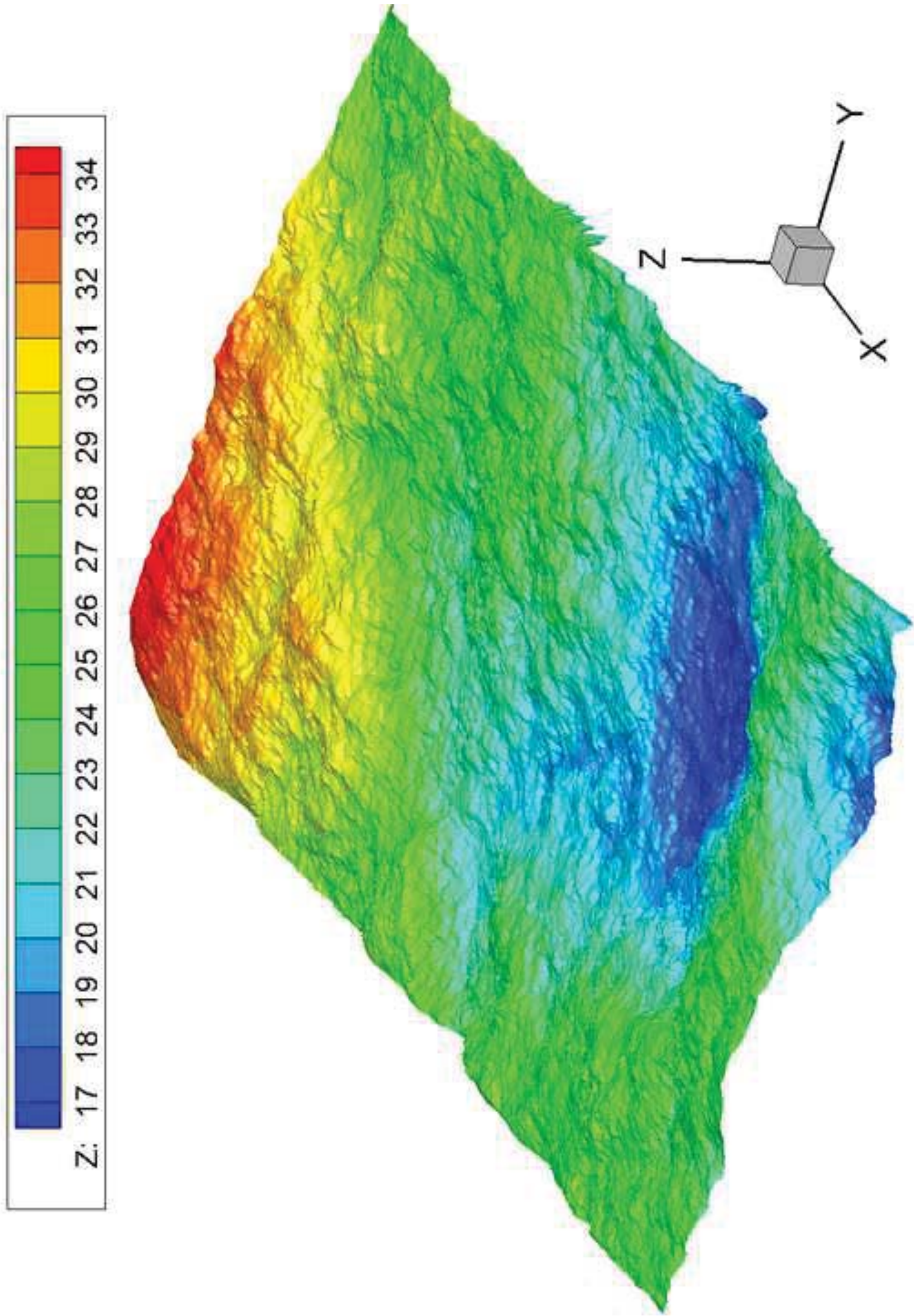



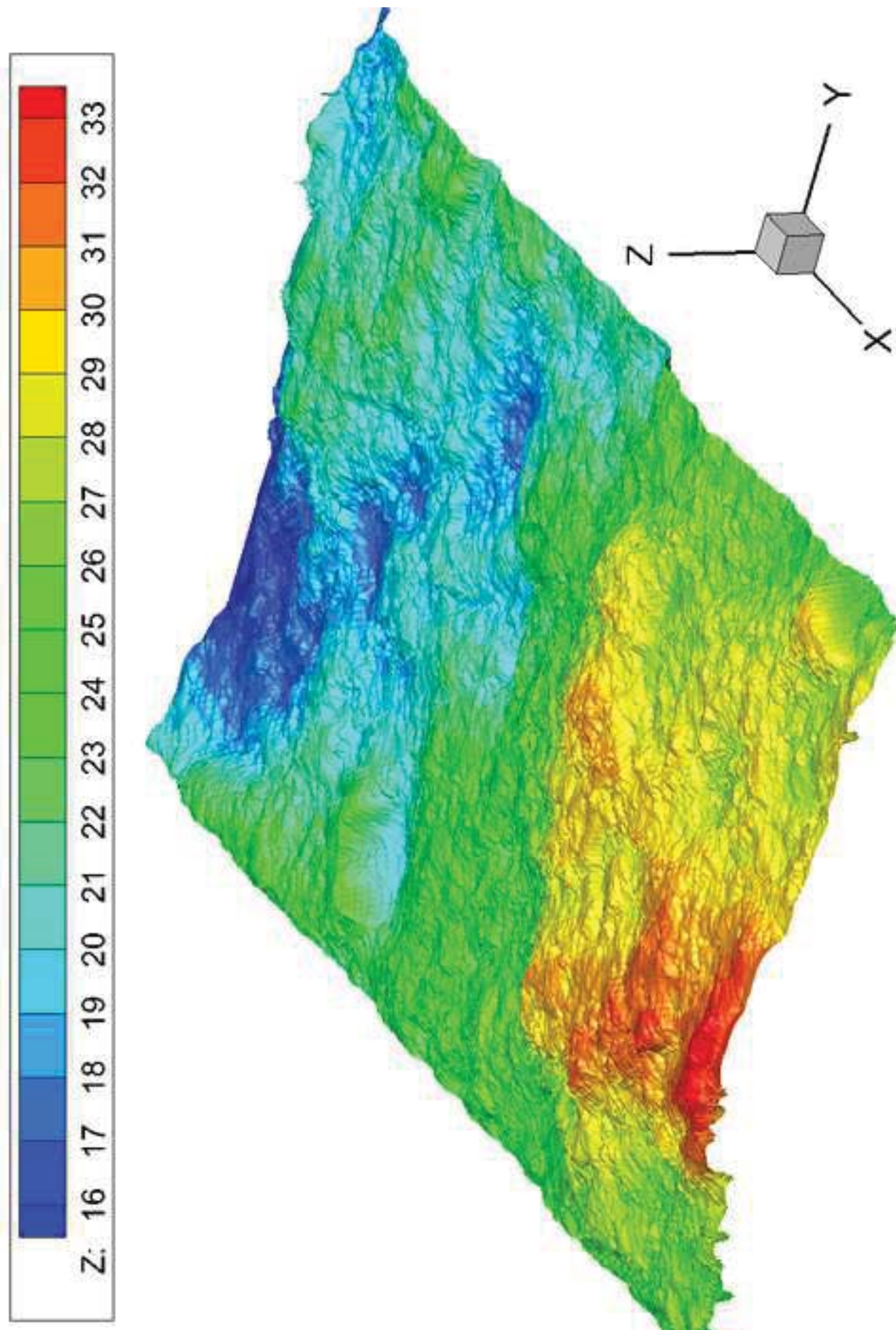


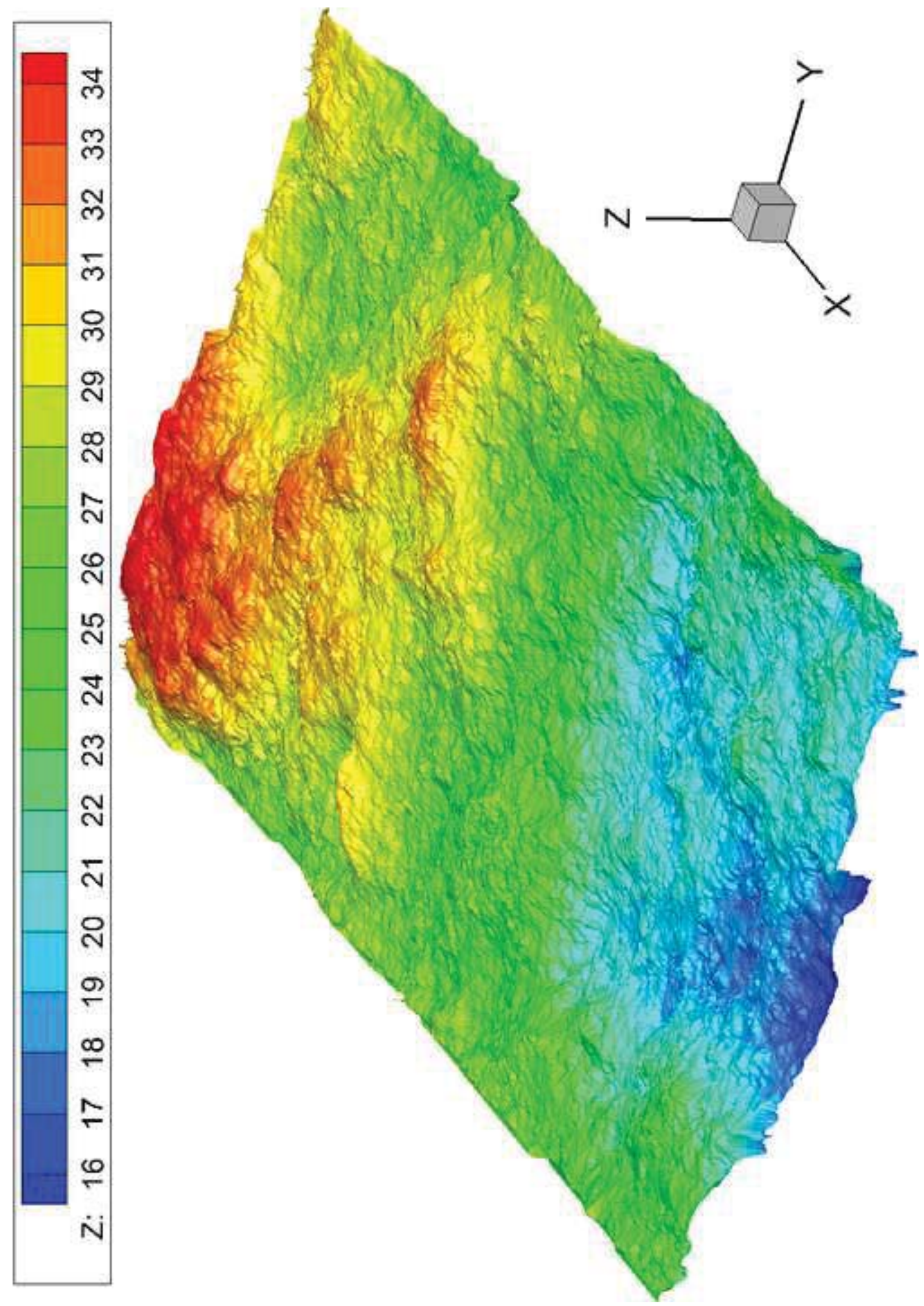




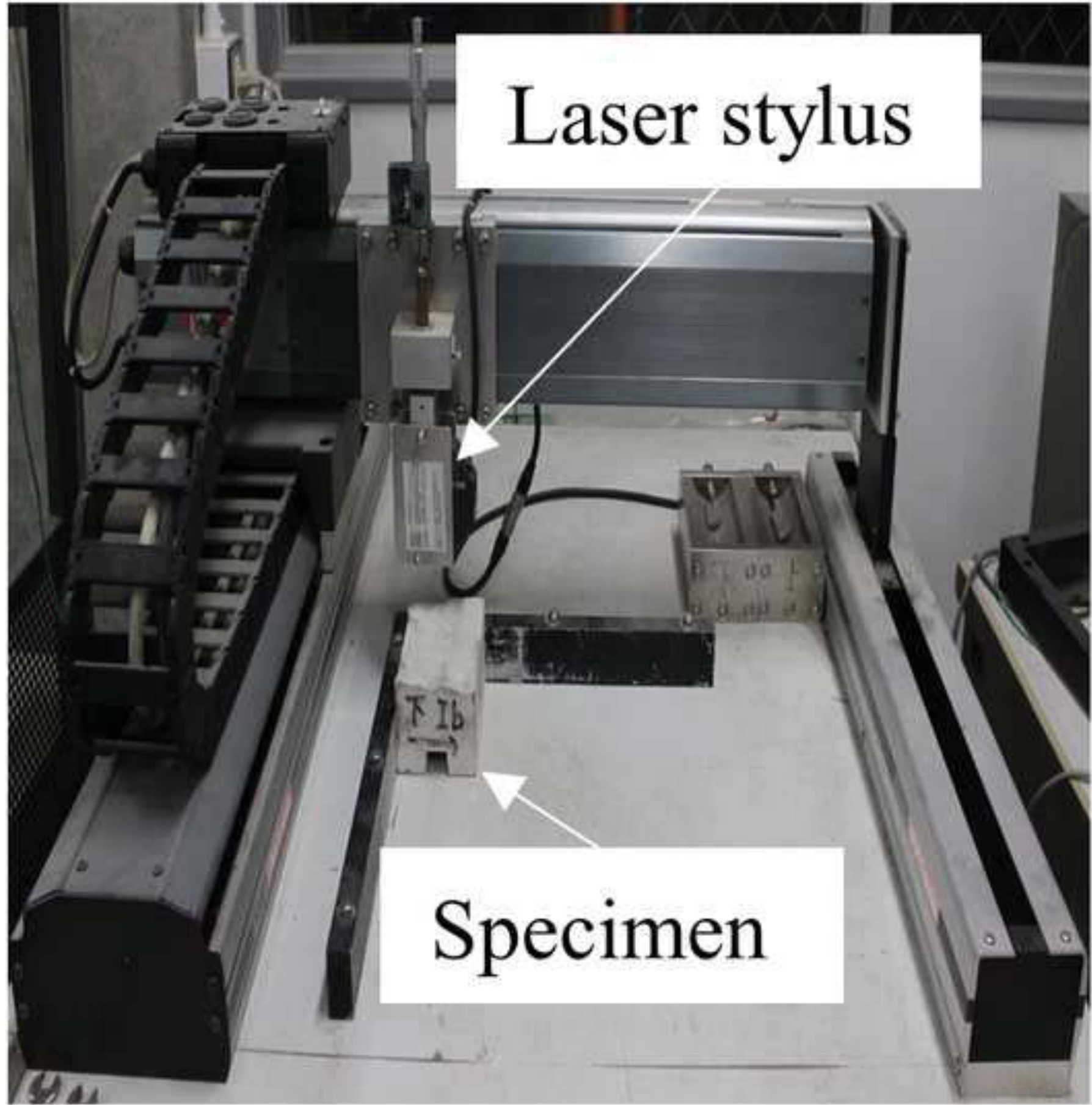




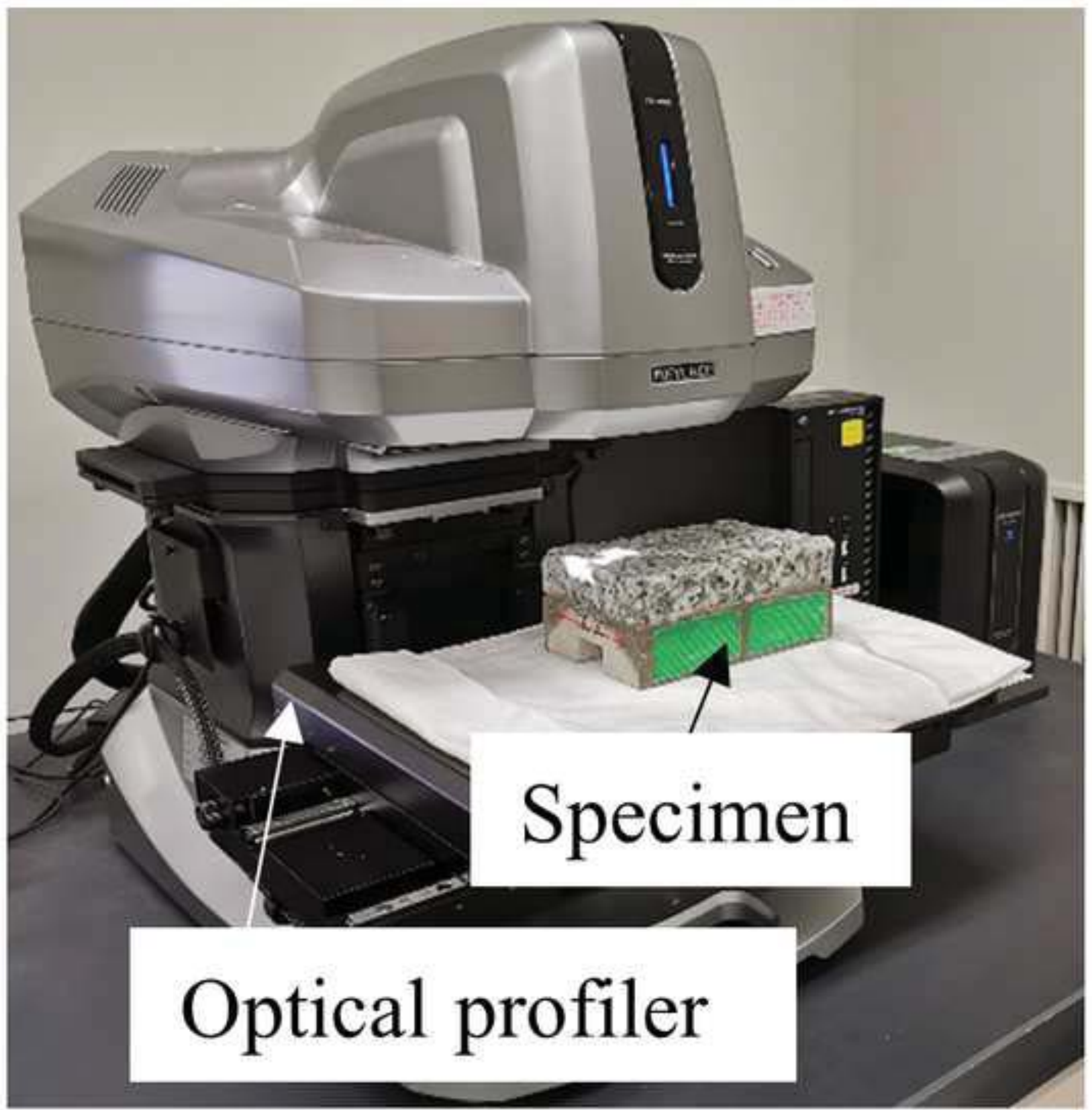




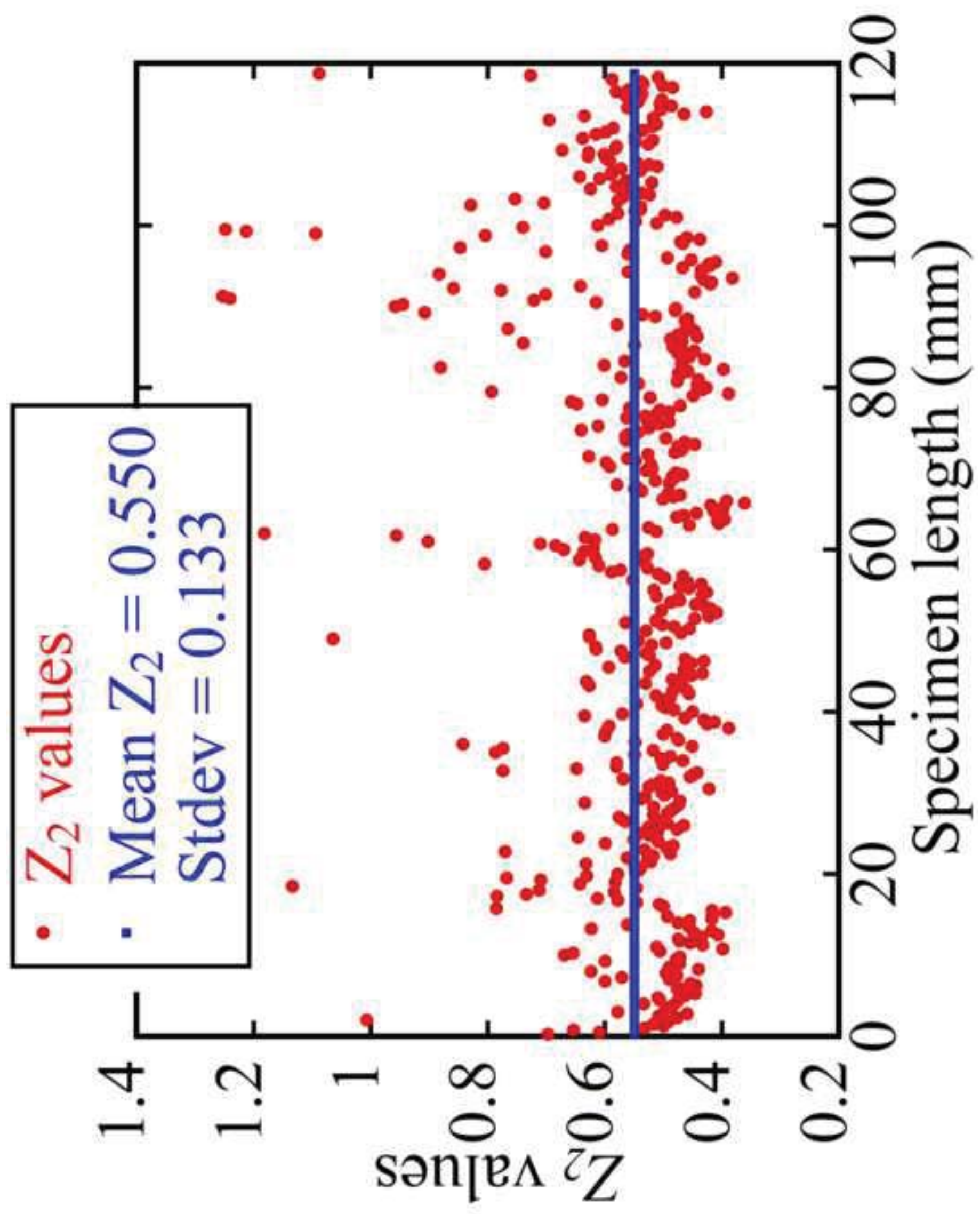




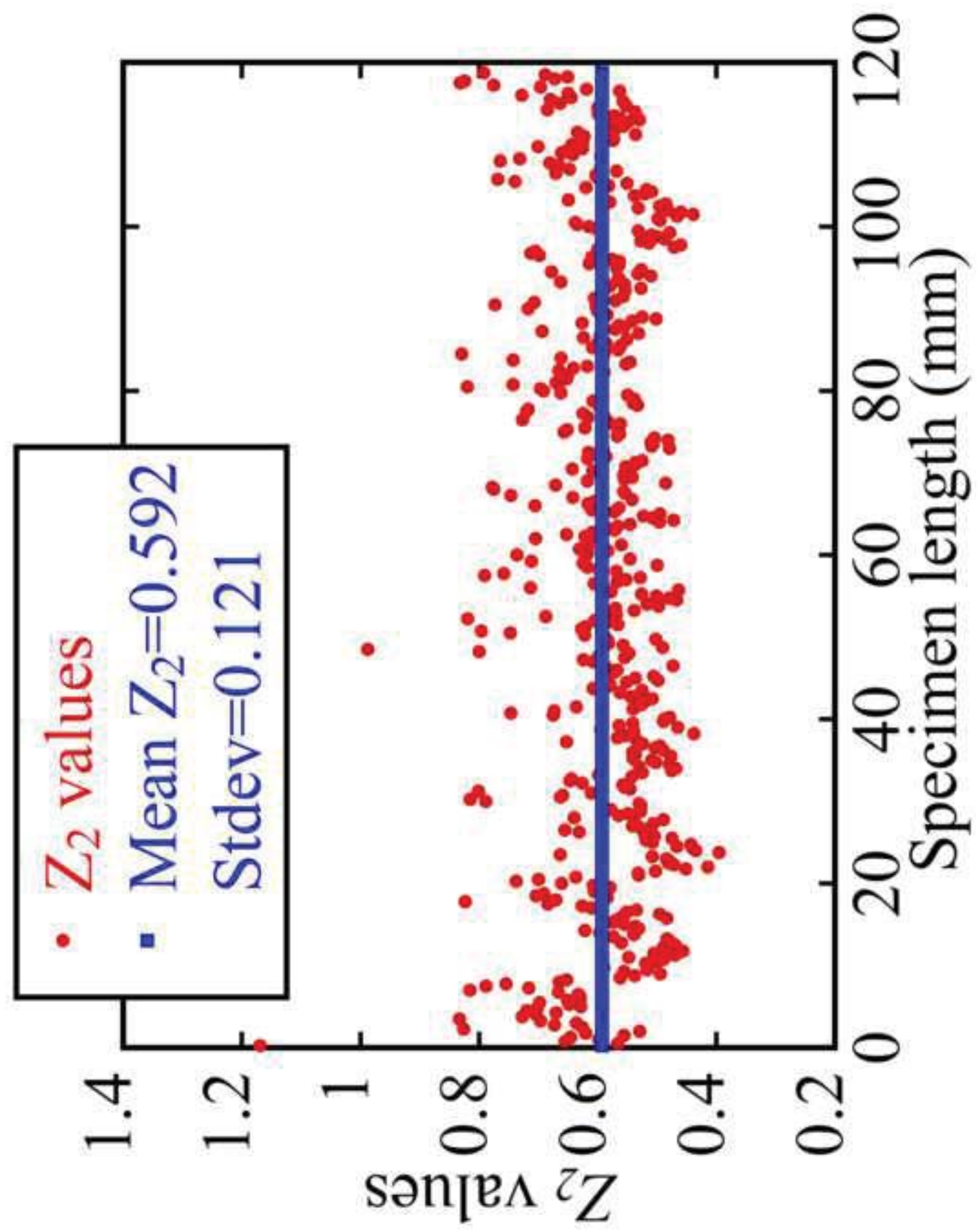




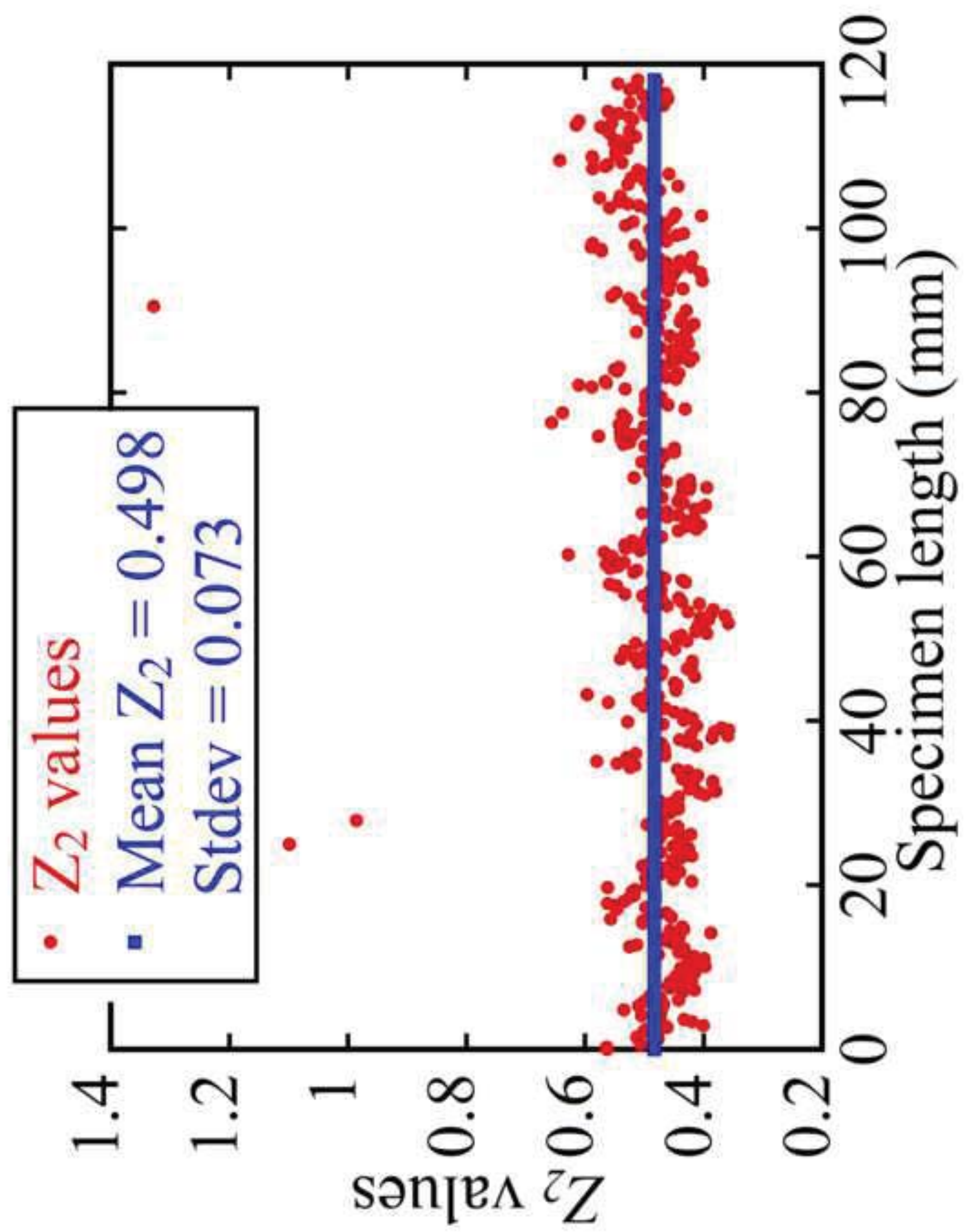




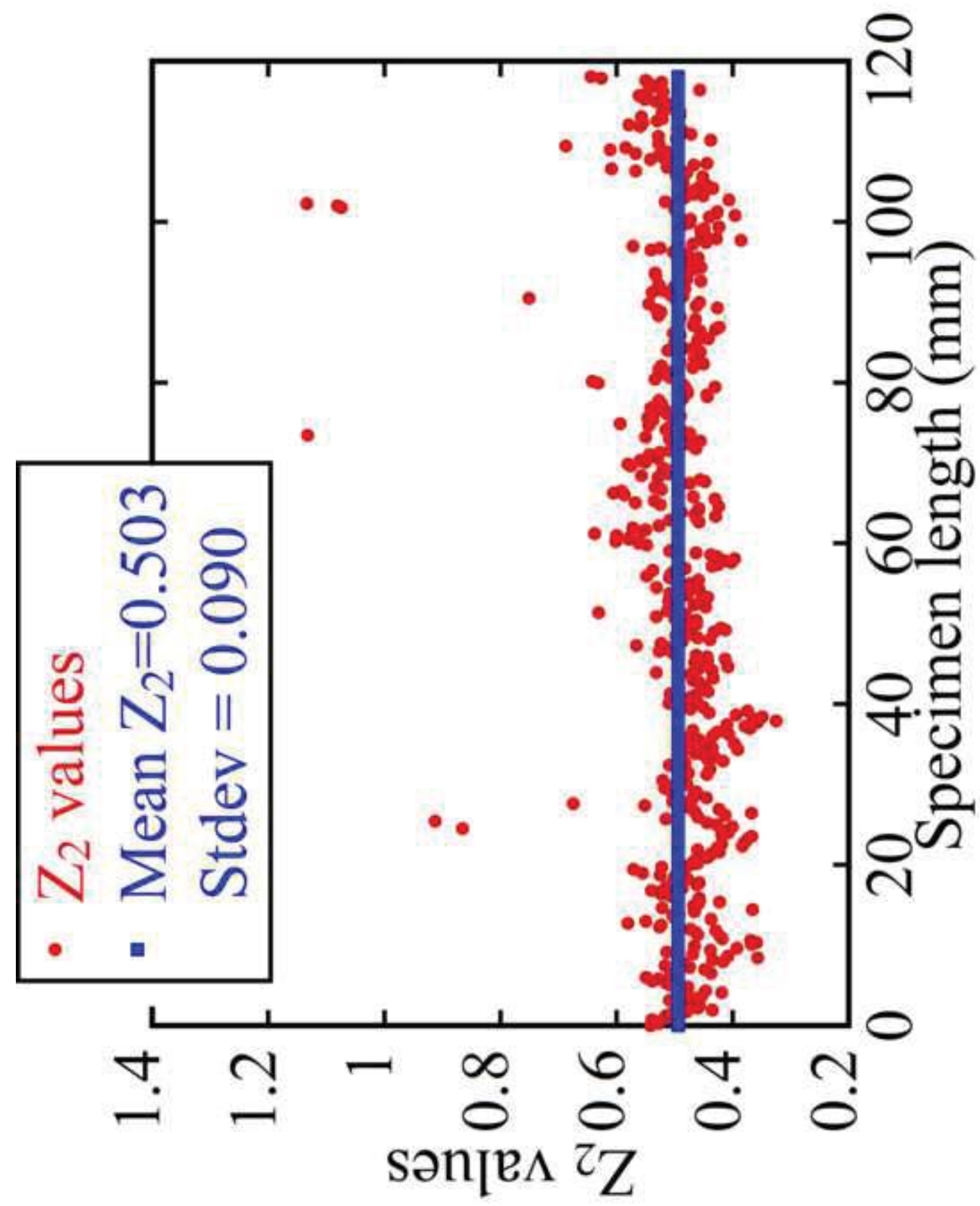




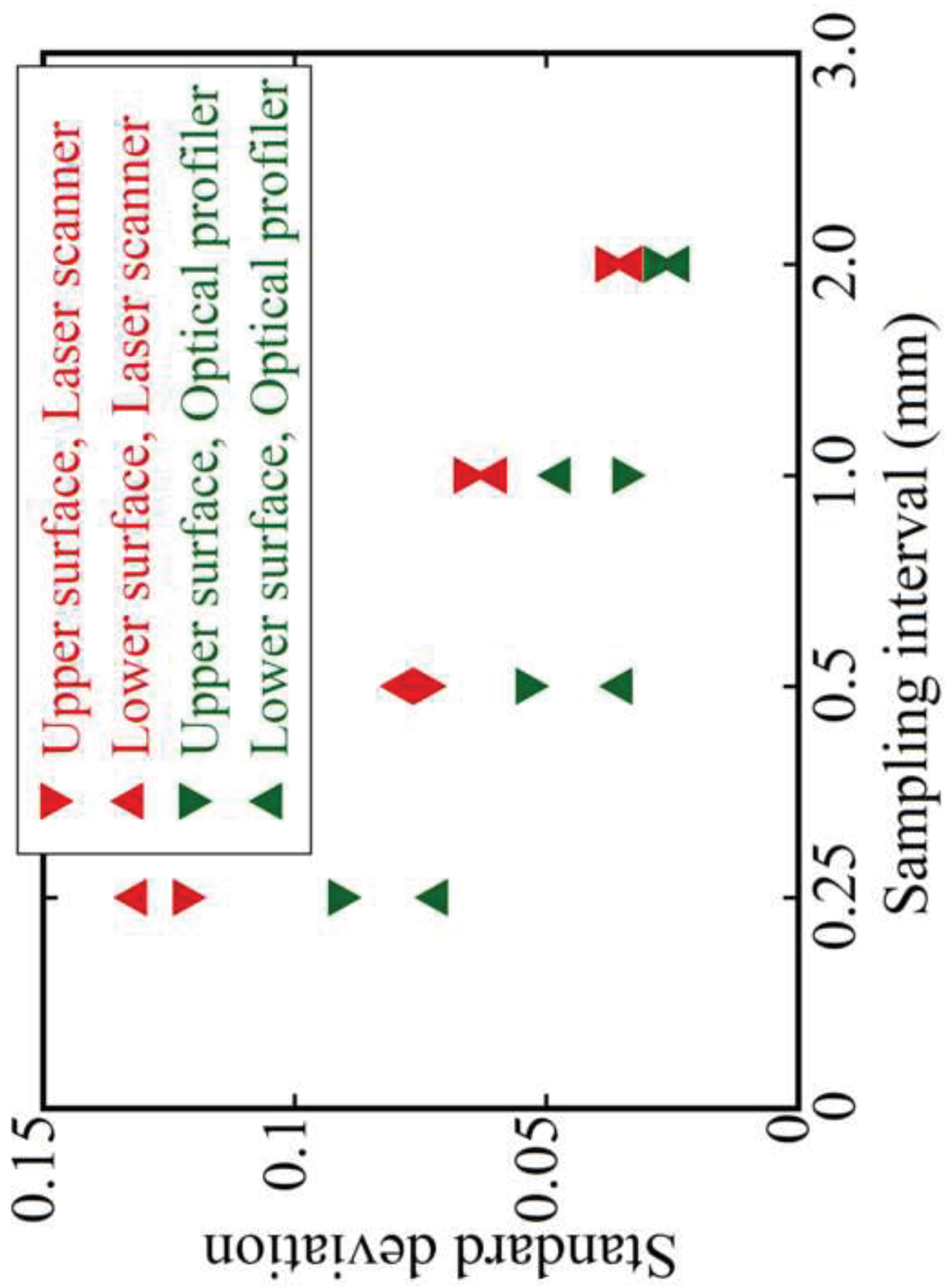




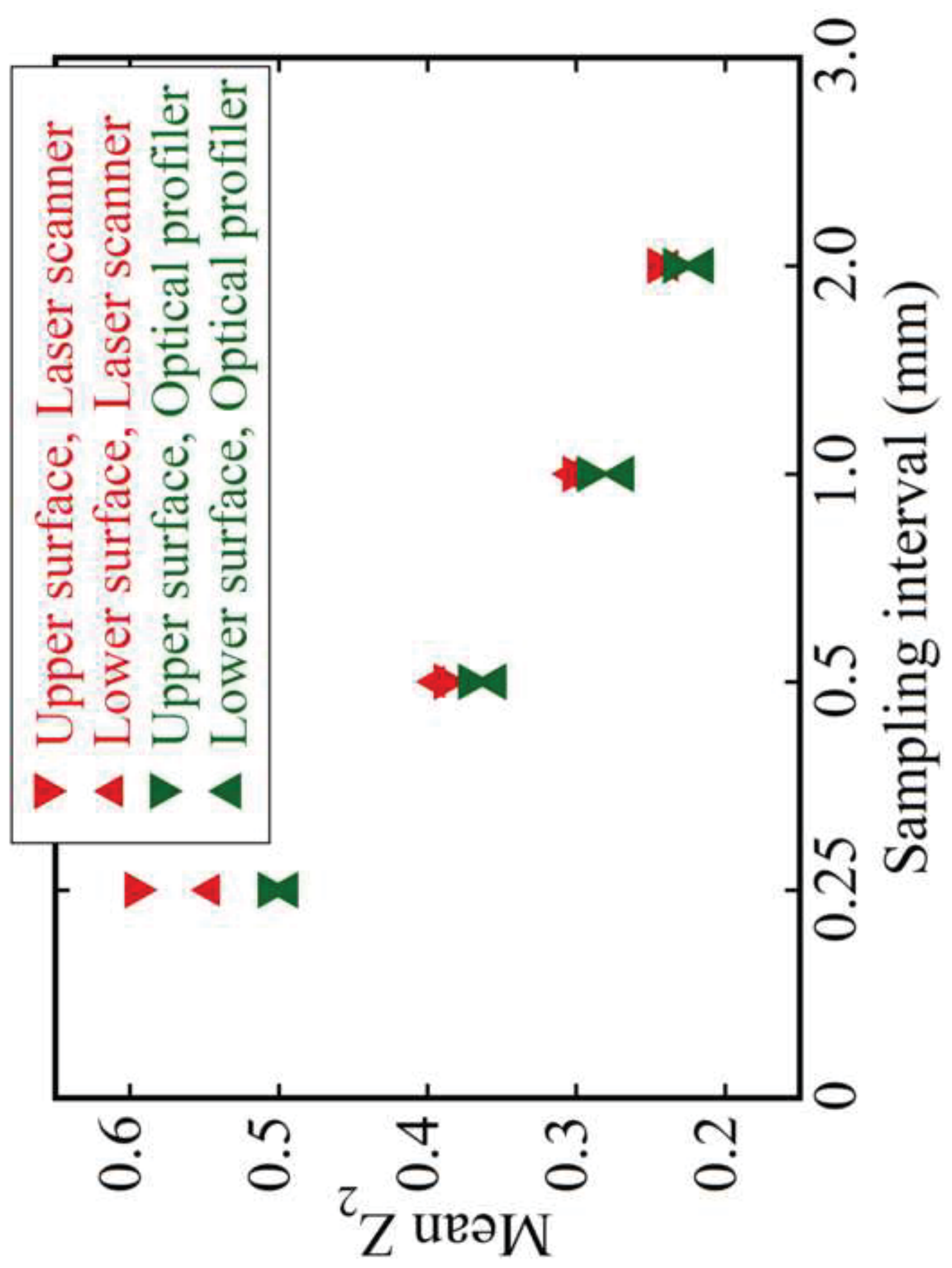




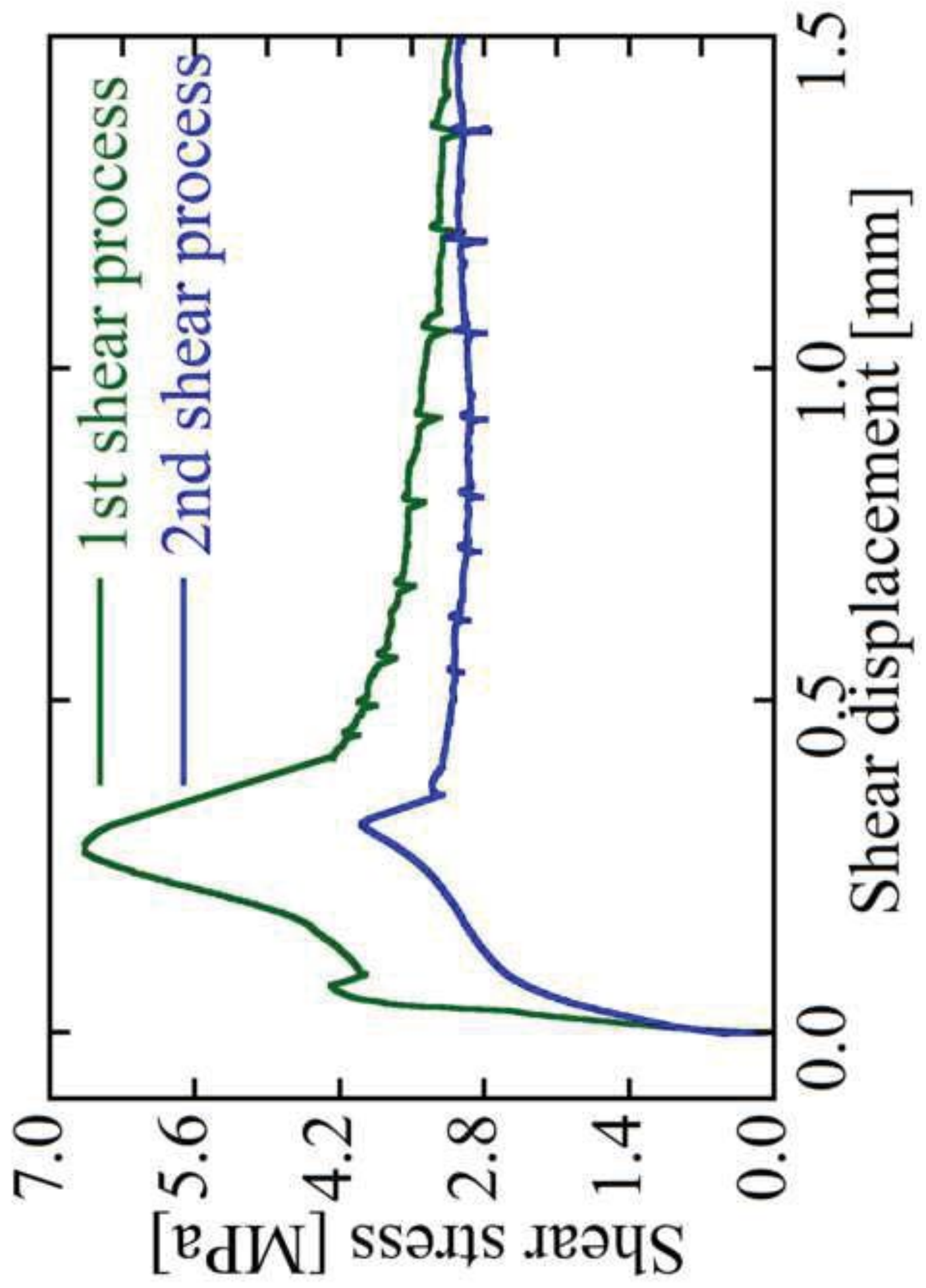




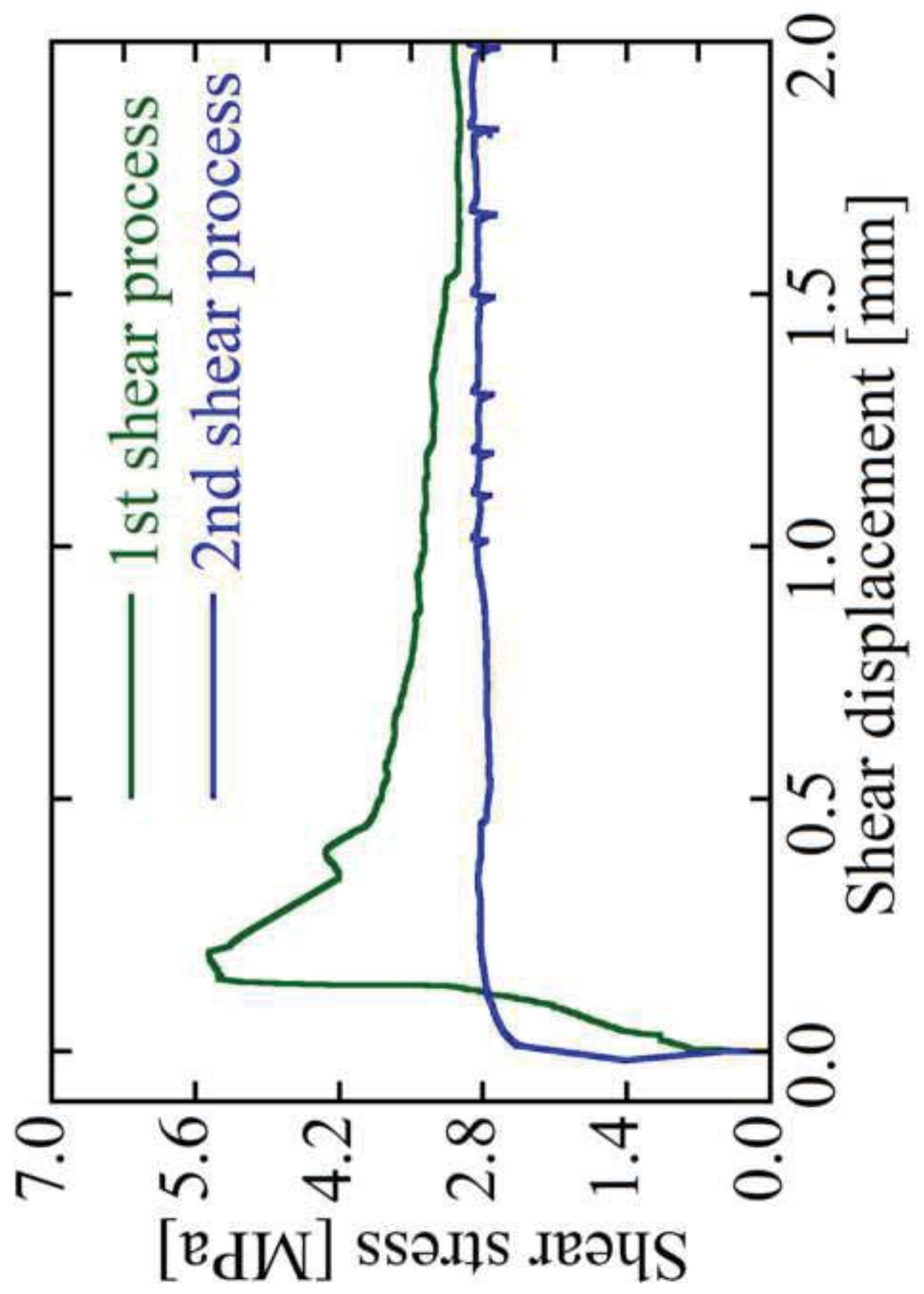




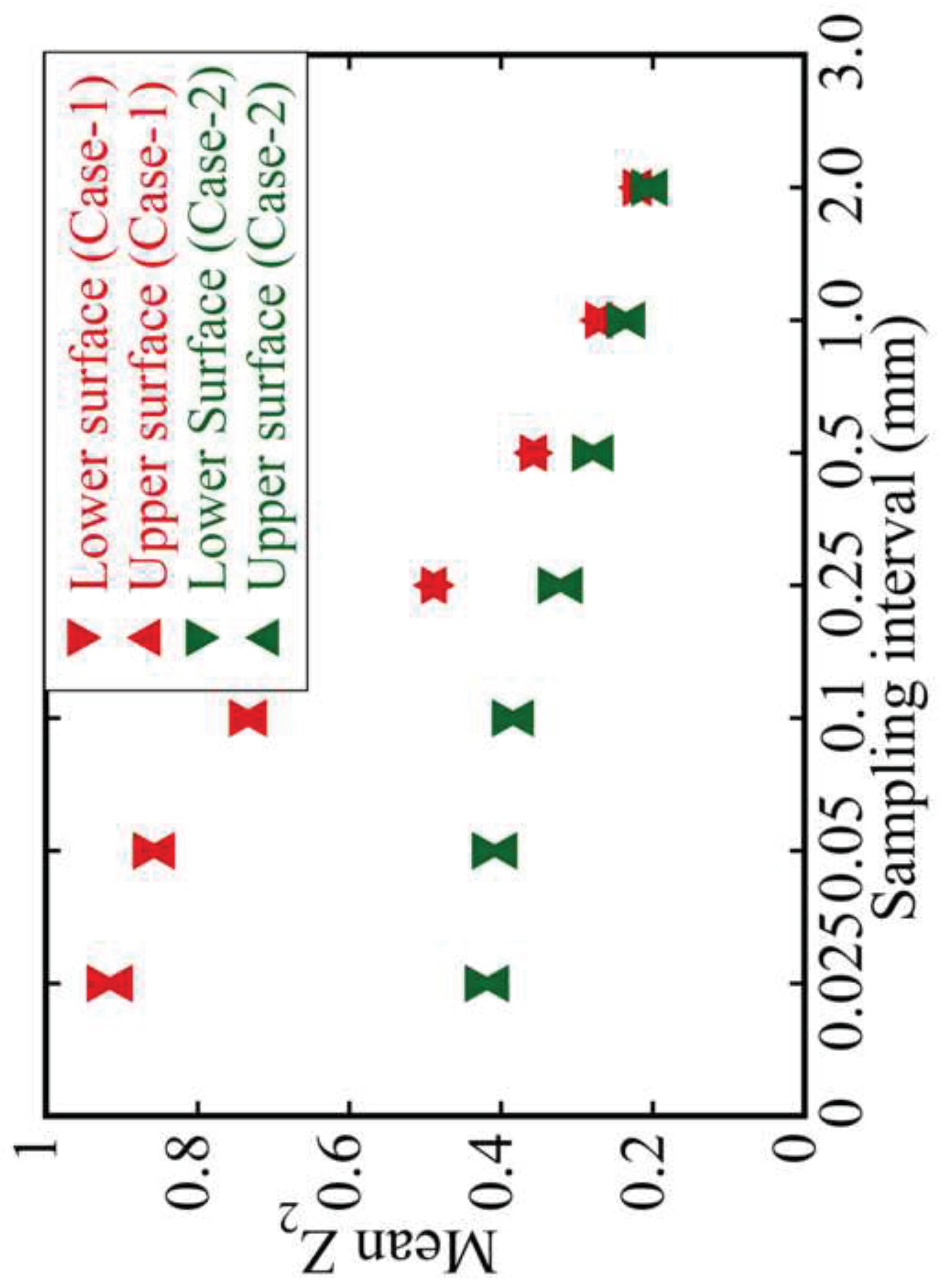




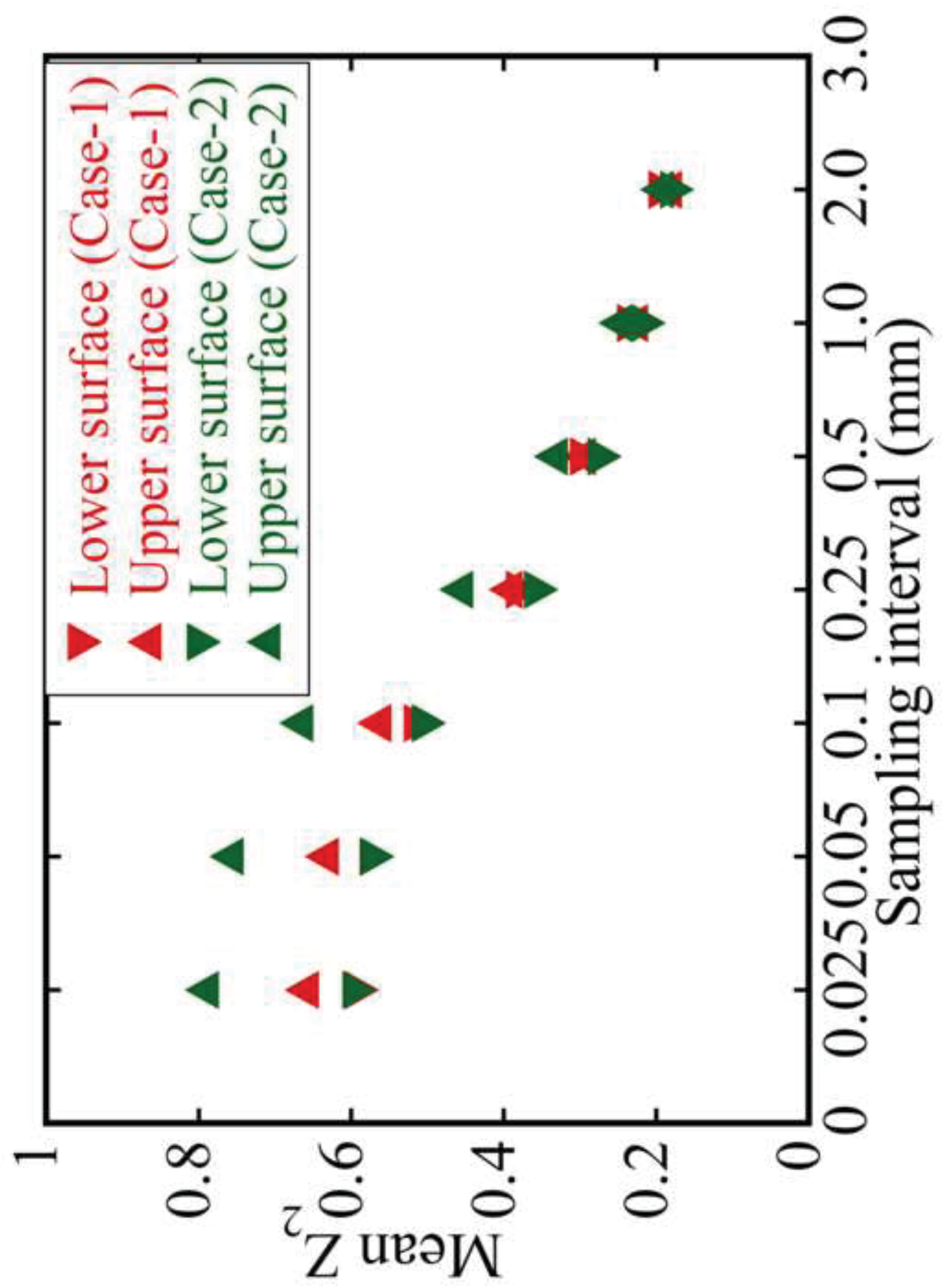




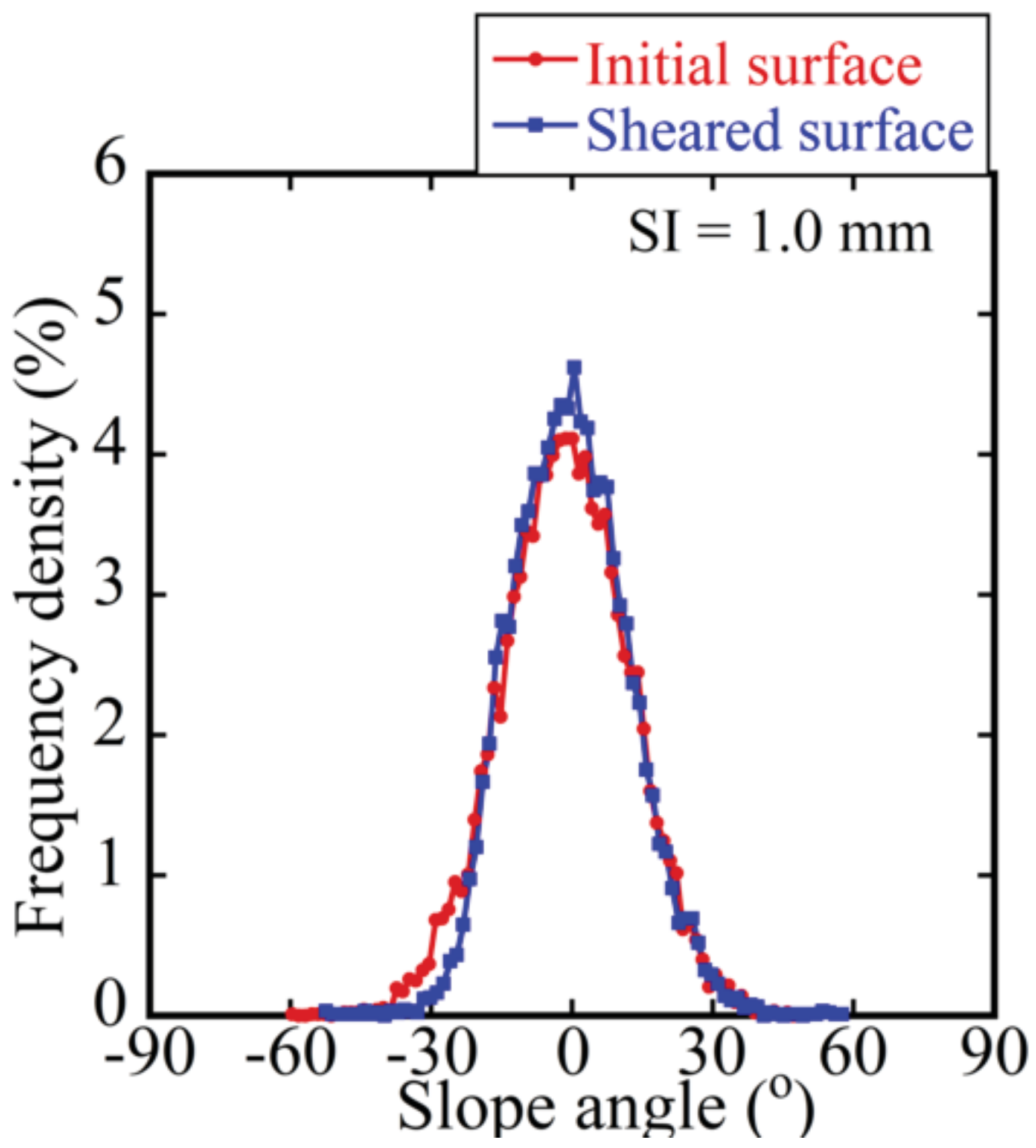




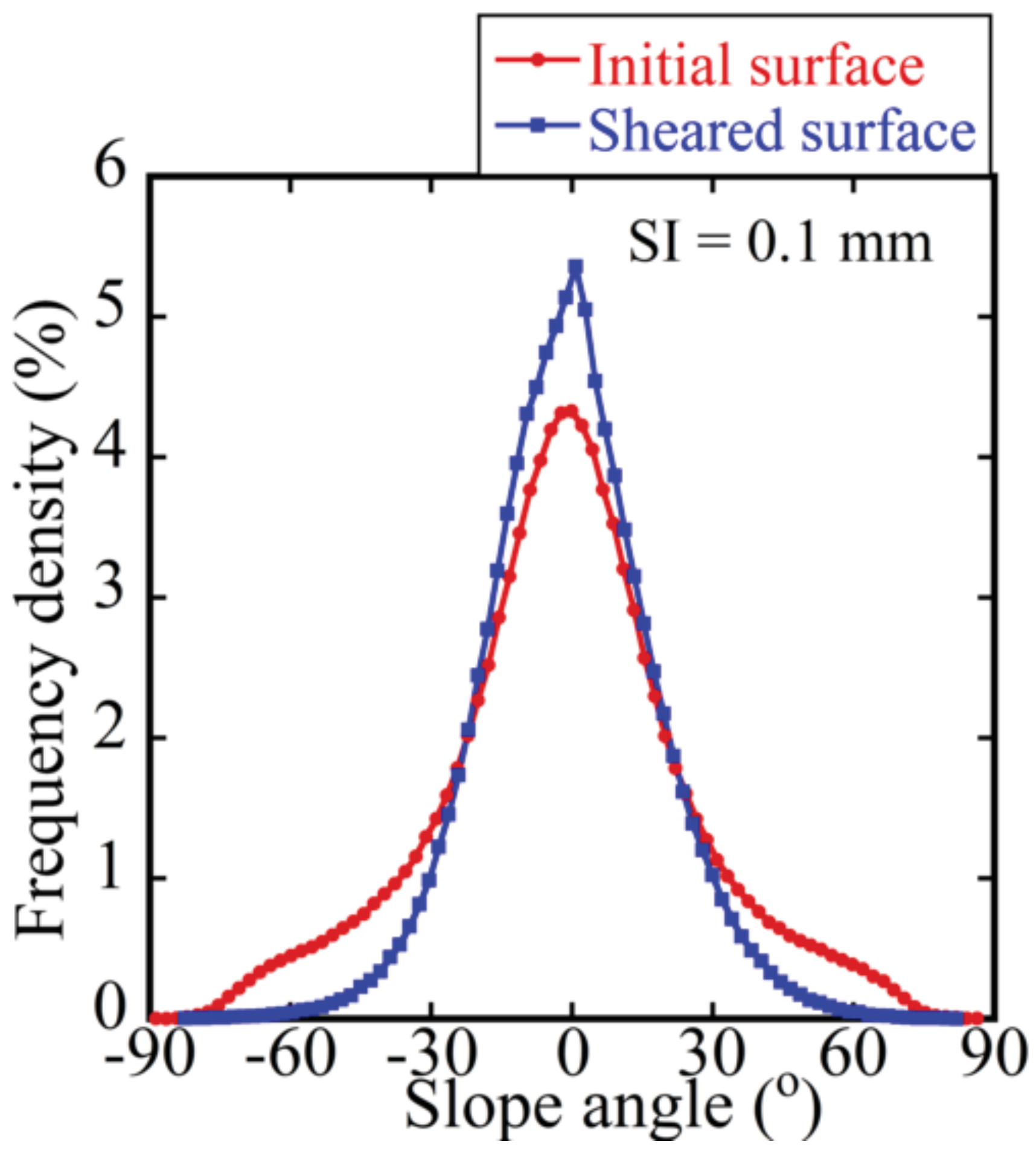




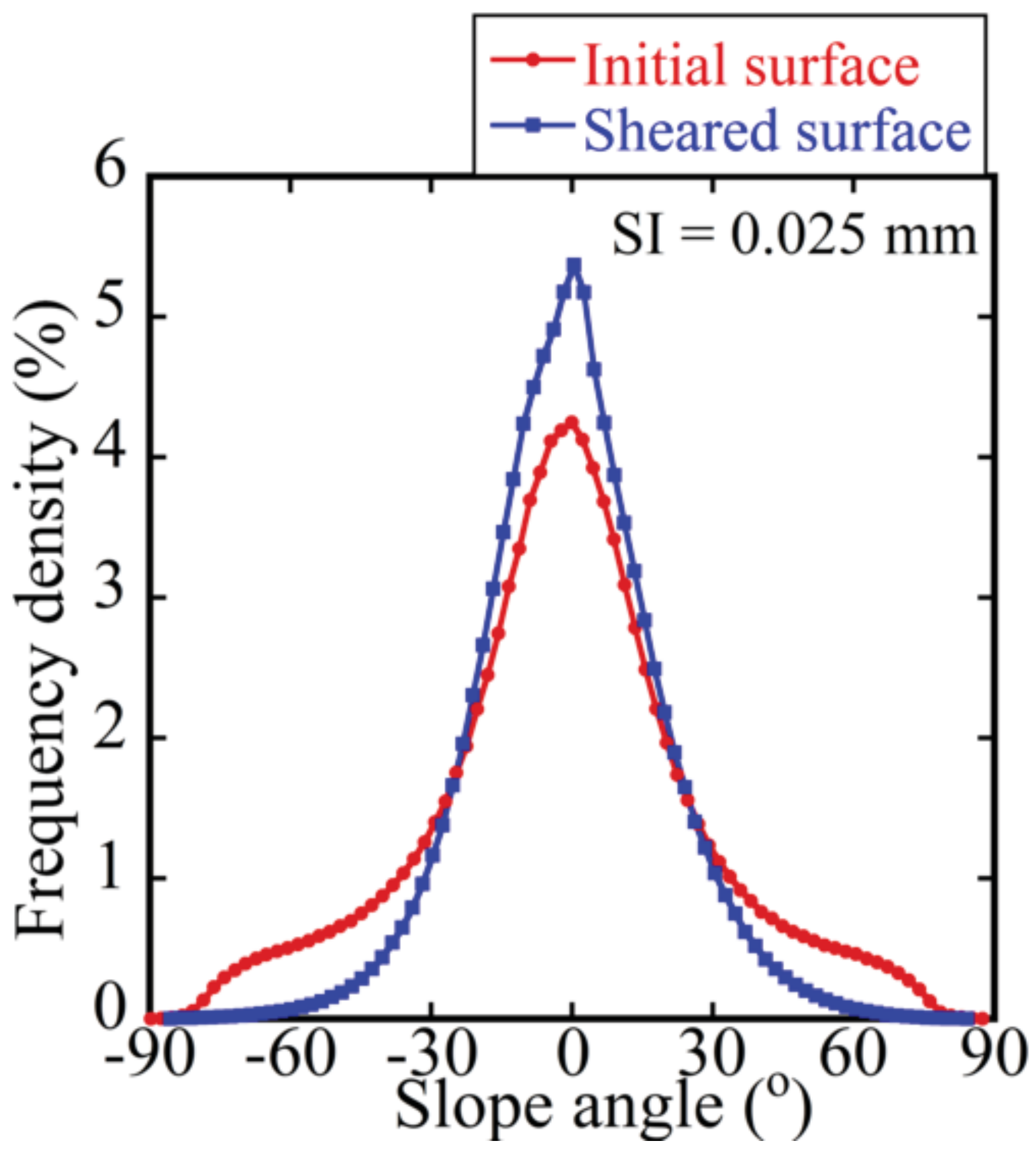




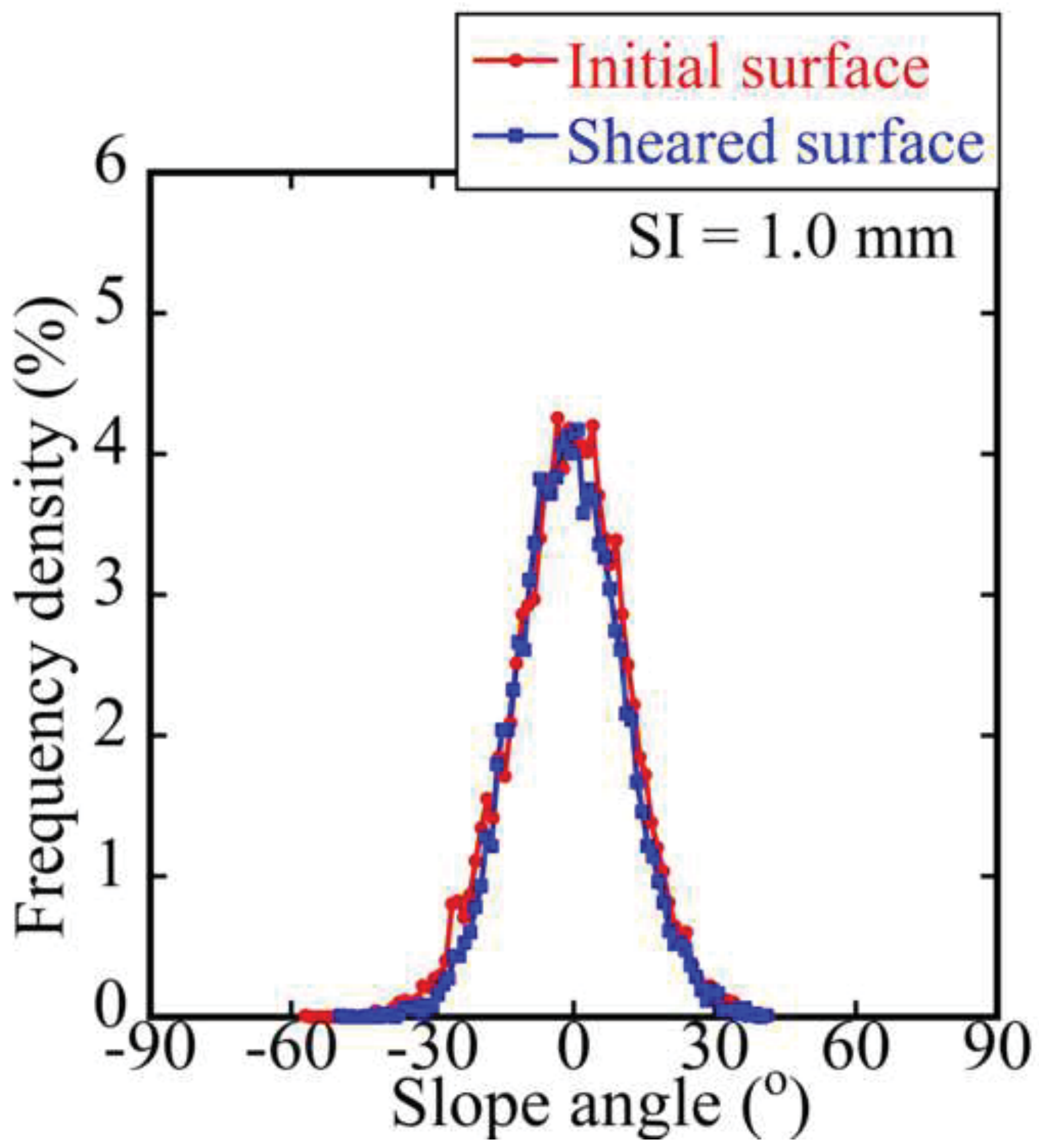




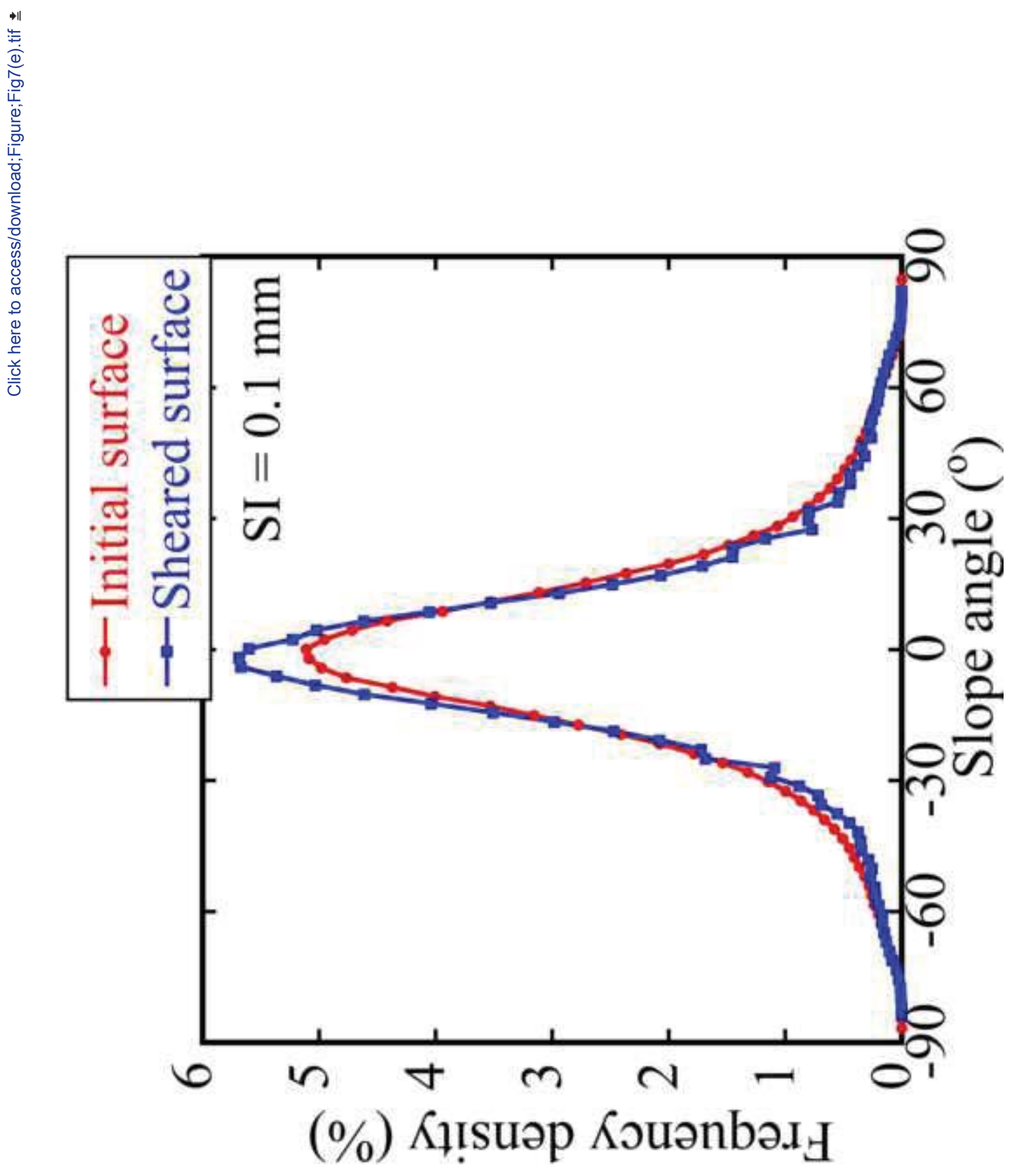




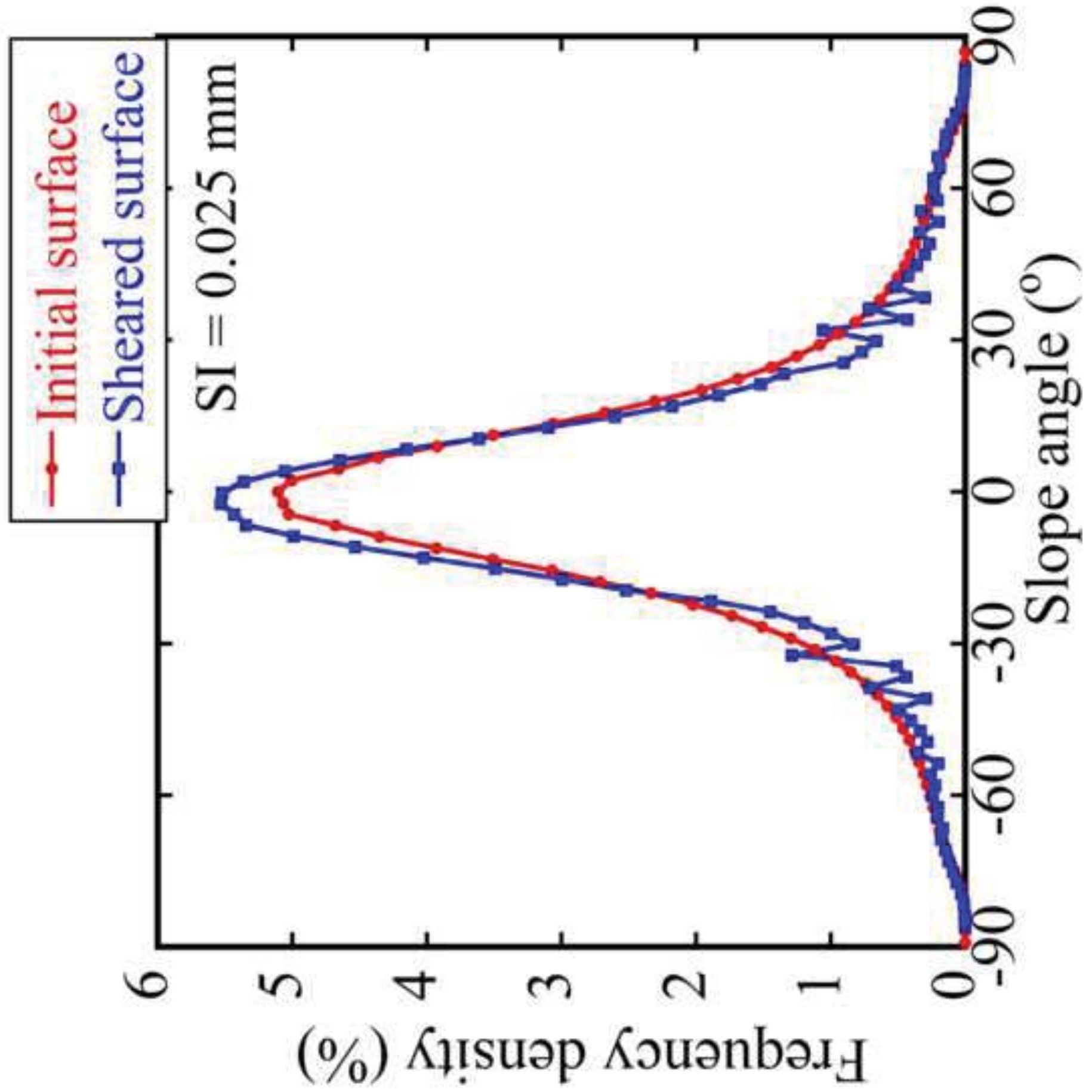




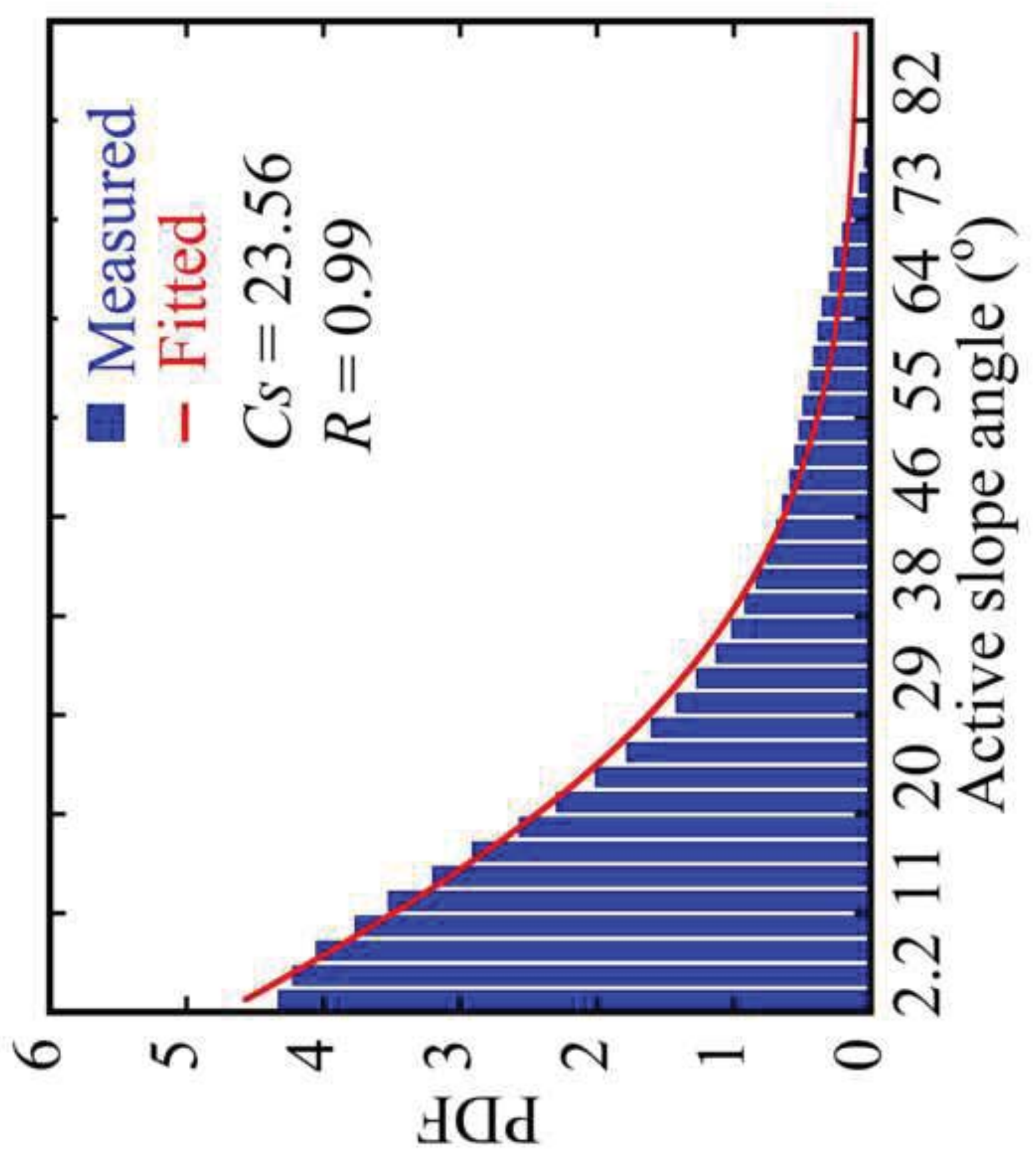




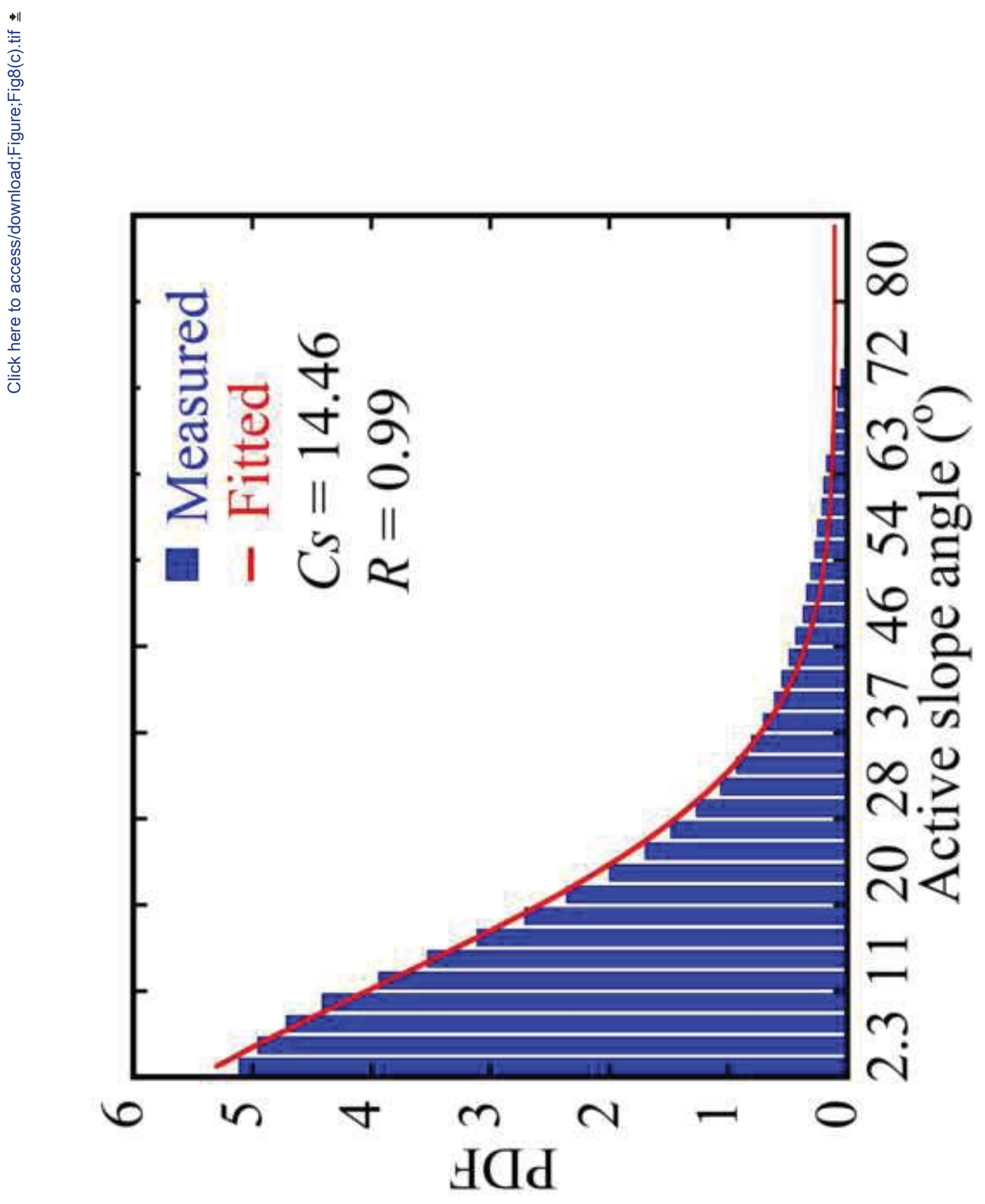




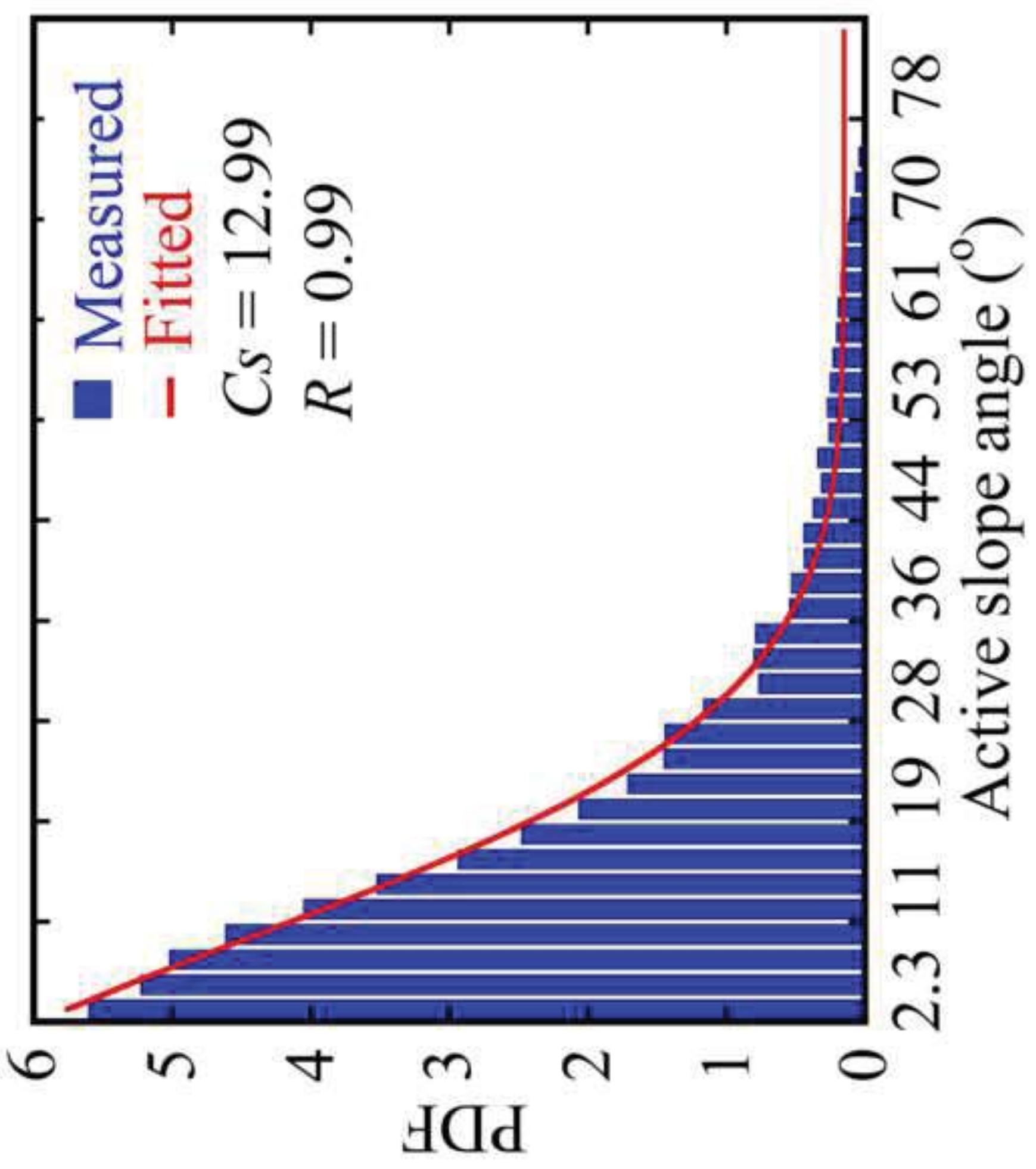




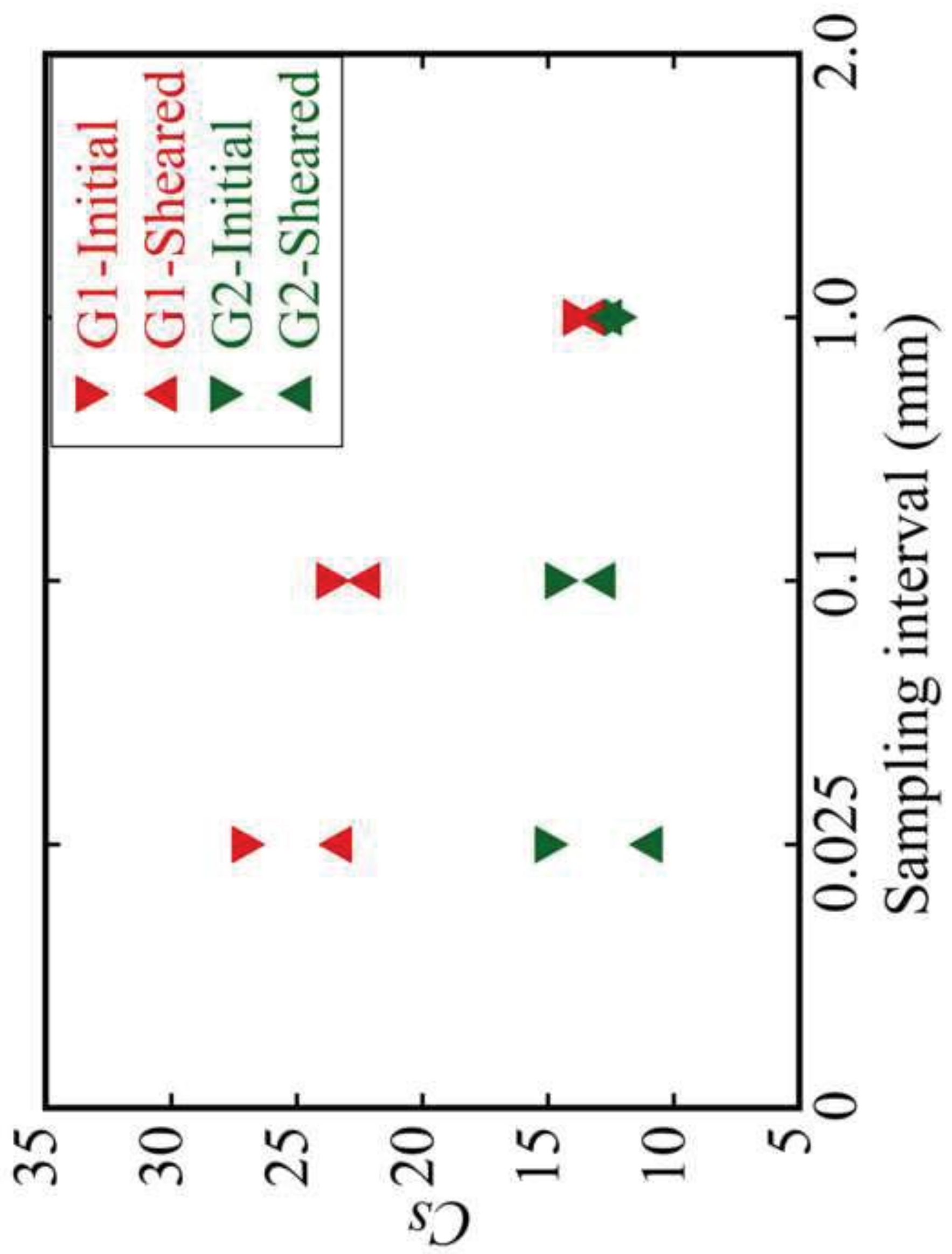



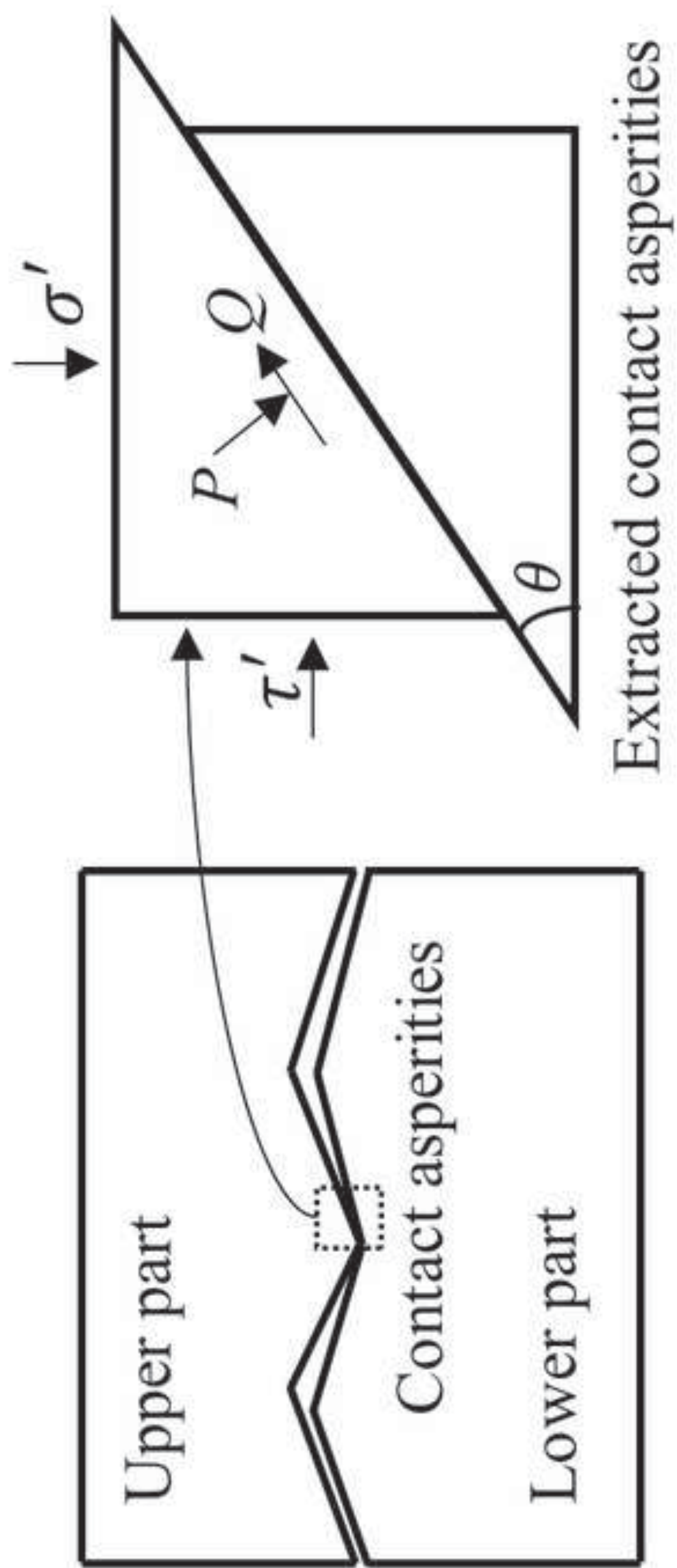
Assume dilation angle $\theta$

Count the number of contacted asperities $A$

(if the asperities angle is larger than $\theta$, then shaved them off)

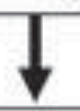

Calculate the normal stress $\left(\sigma_{n}^{\prime}\right)$ applying the contacted asperities

$$
\sigma_{n}^{\prime}=\sigma_{n} \times(\text { Total profiling points } / A)
$$

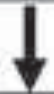

Calculate the shear stress $\left(\tau^{\prime}\right)$ applying the contacted asperities

$$
\tau^{\prime}=\sigma_{n}^{\prime} \tan \left(\phi_{b}+\theta\right)
$$

Calculate the concentrated stress $(P)$ on the rock joint surface

$$
P=\left(\tau \cdot \sin \theta+\sigma_{n}^{\prime} \cos \theta\right) \times \cos \theta
$$

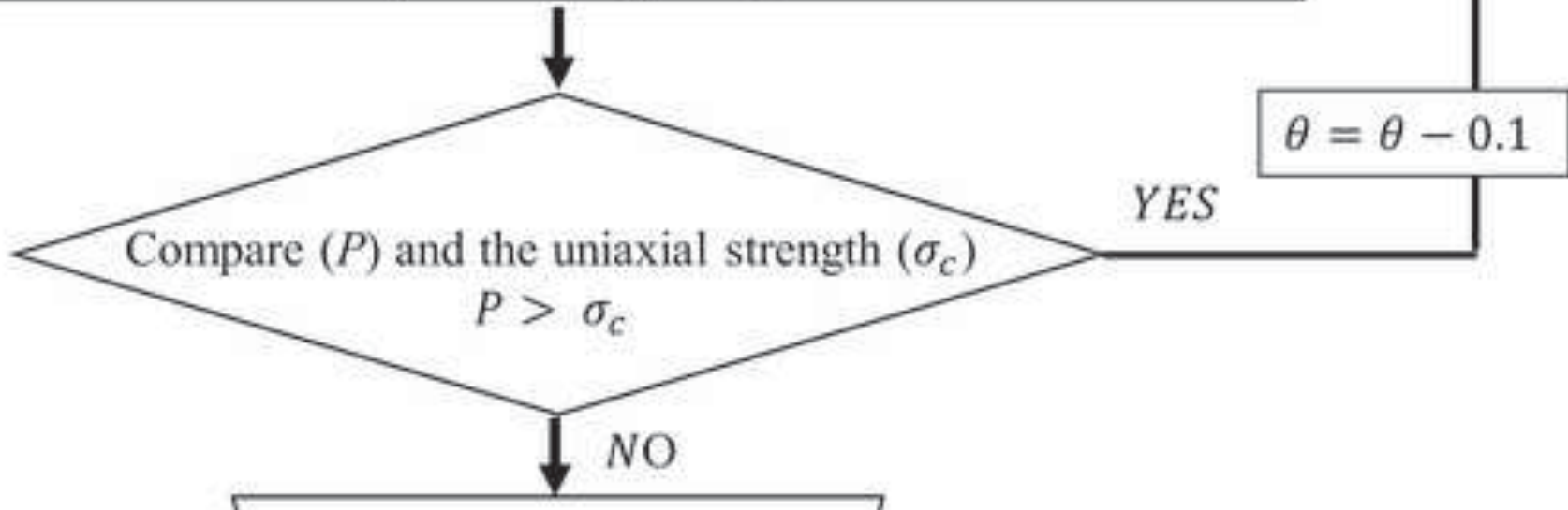

Determine dilation angle $\theta$

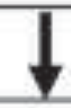

Calculate the shear stress

$$
\tau=\sigma_{n} \tan \left(\phi_{b}+\theta\right)
$$




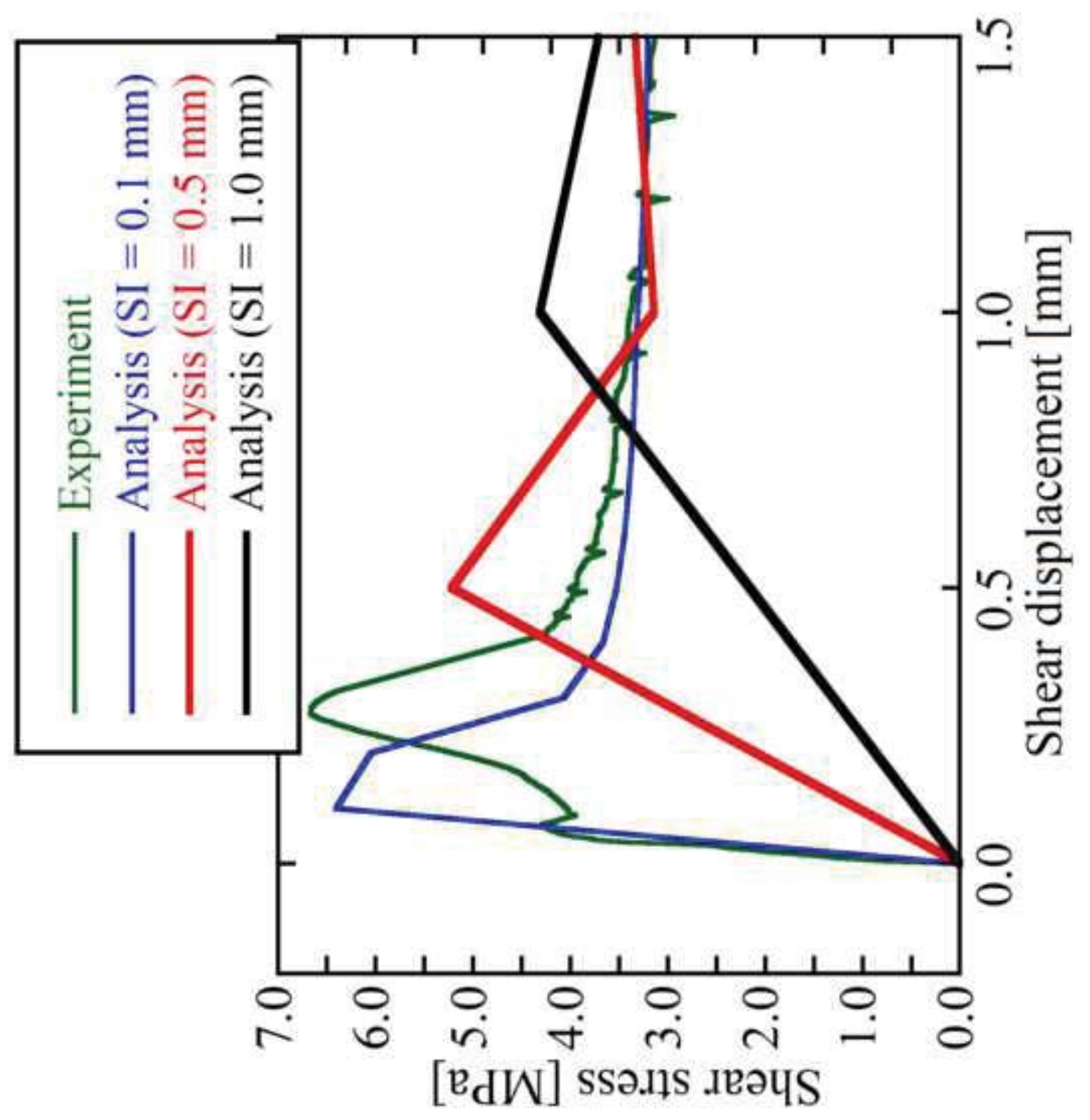




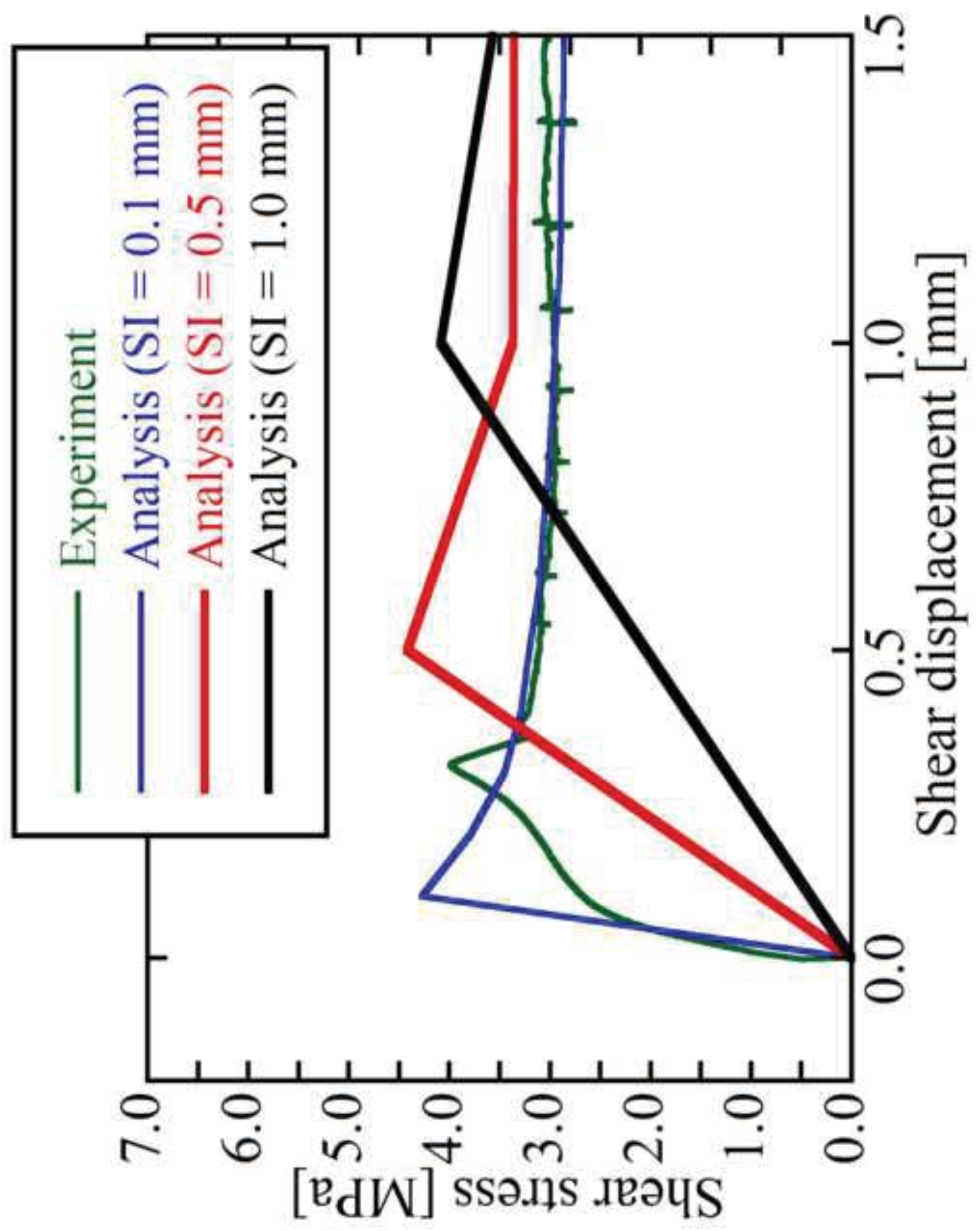




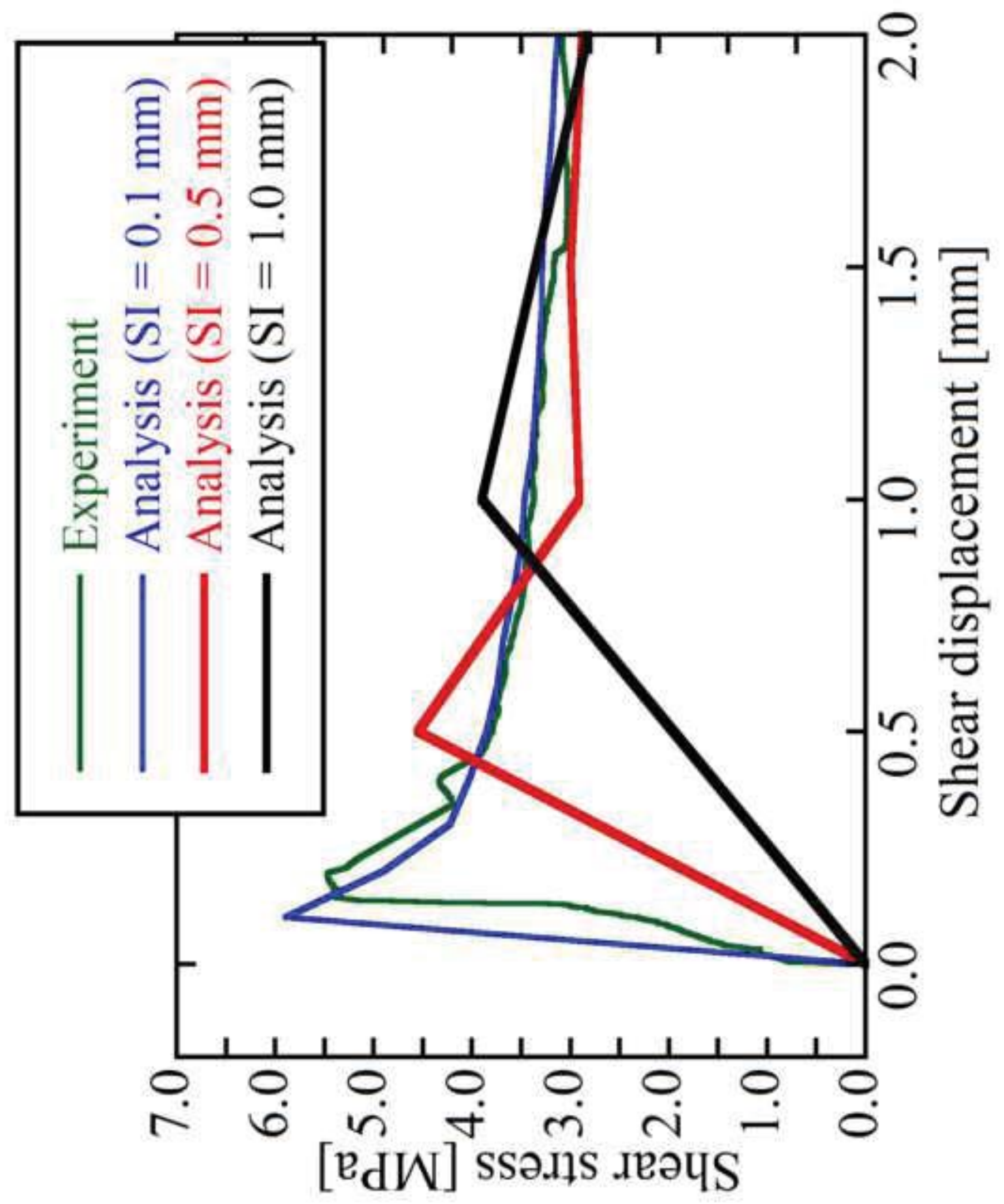




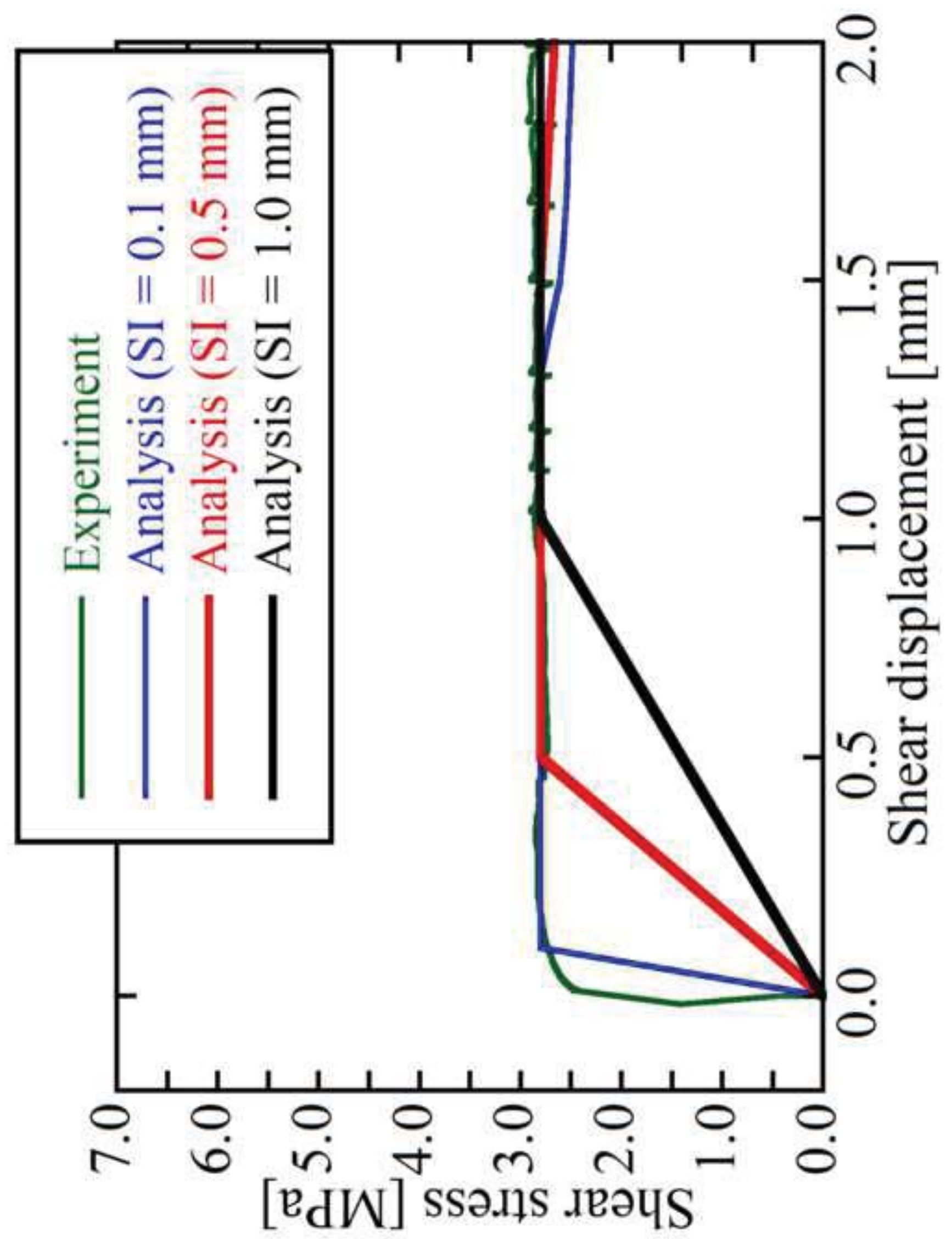




\section{Figures}

Fig. 1. Initial joint surface morphology of specimens: (a) and (b) lower and upper surfaces of G1; (c) and (d) lower and upper surfaces of G2; (e) and (f) lower and upper surfaces of G3; (g) and (h) lower and upper surfaces of G4

Fig. 2. Two kinds of profiling techniques: (a) laser scanner; (b) optical profiler

Fig. 3. Distribution of $Z_{2}$ values in lower and upper surfaces of G1 specimen with two techniques: (a) and (b) profiled data of lower and upper surfaces from laser scanner; (c) and (d) profiled data of lower and upper surfaces from optical profiler.

Fig. 4. (a) Variation in standard deviation of $Z_{2}$ values in lower and upper surfaces of specimen G1 with different sampling intervals; (b) variation in mean $Z_{2}$ values in lower and upper surfaces of specimen G1 with different sampling intervals

Fig. 5. Experimental results of direct shear tests: (a) specimen G1; (b) specimen G2

Fig. 6. Variation in mean $Z_{2}$ values between initial and sheared surfaces with different intervals: (a) specimen G1; (b) specimen G2

Fig. 7. Variation in slope angles between initial and sheared surfaces with different intervals: (a), (b) and (c) sampling intervals of $1.0 \mathrm{~mm}, 0.1 \mathrm{~mm}$ and $0.025 \mathrm{~mm}$ in specimen $\mathrm{G} 1$; (d), (e) and (f) sampling intervals of $1.0 \mathrm{~mm}, 0.1 \mathrm{~mm}$ and $0.025 \mathrm{~mm}$ in specimen $\mathrm{G} 2$

Fig. 8. Probability distribution of active slope angles with a sampling interval of $0.1 \mathrm{~mm}$ : (a) and (b) initial and sheared surface of specimen G1; (c) and (d) initial and sheared surfaces of specimen G2

Fig. 9. Alteration of $C_{s}$ on initial and sheared surfaces with different sampling intervals

Fig. 10. Concept of stress on contact asperities

Fig. 11. Procedures for implementing the mechanical shear model (Kishida and Sakurai 2007) *.

*This figure was reprinted from "Improvement of the mechanical shear model for rock joints considering the bearing effect", Soils and Foundations, Vol. 47, No. 3, Kishida, K., and Sakurai, Y., Fig. A2. Flow chart for Step1, p. 627, Copyright Elsevier (2007), with permission from Elsevier. 
Fig. 12. Comparison between experimental results and analysis results for shear behaviour of rock joints: (a) and (b) first and second shear processes of specimen G1; (c) and (d) first and second shear processes of specimen G2 